\title{
Continental-scale quantification of post-fire vegetation greenness recovery in temperate and boreal North America
}

\author{
Jia Yang $^{\mathrm{a}}$, Shufen Pan ${ }^{\mathrm{a}, \mathrm{b}}$, Shree Dangal ${ }^{\mathrm{a}}$, Bowen Zhang ${ }^{\mathrm{a}}$, Siyuan Wang ${ }^{\mathrm{a}, \mathrm{c}}$, Hanqin Tian ${ }^{\mathrm{a}, \mathrm{b}, *}$

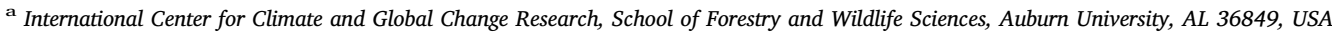 \\ b State Key Laboratory of Urban and Regional Ecology, Research Center for Eco-Environmental Sciences, Chinese Academy of Sciences, Beijing 100085, China \\ ${ }^{c}$ Key Laboratory of Digital Earth, Institute of Remote Sensing and Digital Earth, Chinese Academy of Science, Beijing 100101, China
}

\section{A R T I C L E I N F O}

\section{Keywords:}

Fire regimes

Natural disturbance

Vegetation recovery

Remote sensing

Temperate and boreal ecosystems

\begin{abstract}
A B S T R A C T
Knowledge and information of post-fire vegetation recovery are essential for our understanding of ecosystem stability and resilience in response to present and future disturbances. Although previous studies have examined the post-fire vegetation recovery at landscape and regional levels, the lack of continent-wide analysis limits our understanding of fire effect on vegetation recovery across ecoregions and climate zones. With advanced technology in satellite observations as well as large-scale database development, it is possible for us to explore the large-scale effect of concurrent and lagged responses of terrestrial ecosystems to fire disturbances. In this study, we investigated the recovery of vegetation greenness in the early post-fire period in North America by integrating two national-level fire perimeter datasets and multiple Moderate Resolution Imaging Spectroradiometer (MODIS) products. We developed a new algorithm to estimate fire effect on the Normalized Difference Vegetation Index (NDVI) by comparing fire pixels with their surrounding unburned pixels. Our results showed the fire effect on needleleaf trees was stronger than on other vegetation types, and the high-latitude ecoregions had larger NDVI reduction and longer recovery time than the mid-latitude ecoregions. We also found the variations in vegetation composition and fire severity can explain a large fraction of post-fire vegetation greenness recovery. Our satellite-based analysis showed a longer NDVI recovery time than the existing estimates, which indicates a stronger fire effect on ecosystems than previously thought. Findings in this study indicate that more sophisticated parameterization schemes of fire severity and post-fire vegetation recovery are needed for the vegetation-fire models to better simulate the terrestrial carbon cycling and climate-ecosystem feedbacks.
\end{abstract}

\section{Introduction}

Fire is a widespread land disturbance across the globe (Bond et al., 2005; Bowman et al., 2009; Chuvieco et al., 2016; van der Werf et al., 2010), which substantially alters vegetation composition, terrestrial biogeochemical cycles, and global ecosystem-climate feedbacks (Bond et al., 2005; Littell et al., 2016; Randerson et al., 2006; Rogers et al., 2013; Ward et al., 2012; Yang et al., 2015a). While fires have been wellrecognized as critical components in the Earth System Model (ESM) (e.g., Arora and Boer, 2005; Lasslop et al., 2014; Li et al., 2012), parametrization schemes to simulate fire effects on ecosystem processes diverge significantly among current fire models. It is still unclear which type of scheme has better performance in representing fire effect (Hantson et al., 2016). Moreover, the simulation of post-fire vegetation recovery has not been validated against large-scale benchmark data sets and remains one of the major challenges in developing vegetation-fire models. This gap may lead to large uncertainties in understanding fire effects on biogeochemical processes (Tian et al., 2016) and their potential feedbacks to the climate system (Rogers et al., 2013). Therefore, knowledge of post-fire vegetation recovery and large-scale benchmark data sets are essential for fire model development and validation (Kelley et al., 2013; Hantson et al., 2016; Yang et al., 2015b).

Remote sensing-based estimates provide useful information for validating and constraining model results of fire effects across multiple spatial scales. At the landscape and ecosystem scales, the high-resolution optical imagery (Meng et al., 2017; Quintano et al., 2013) and airborne LiDAR data (McCarley et al., 2017) have been applied for quantifying fire severity and examining the post-fire vegetation dynamics (Bolton et al., 2015; Fernandez-Manso et al., 2016; Meng et al., 2015; Storey et al., 2016; Wulder et al., 2009). These high-resolution remote sensing imageries have high accuracy in vegetation recovery assessment especially for the geographically fragmented stands. At the regional scale, the relative coarse-resolution satellite imageries (such as AVHRR and MODIS) are more popular in investigating post-fire

\footnotetext{
* Corresponding author at: School of Forestry and Wildlife Sciences, SFWS Building, 602 Duncan Drive, Auburn University, AL 36849, USA.

E-mail address: tianhan@auburn.edu (H. Tian).
} 

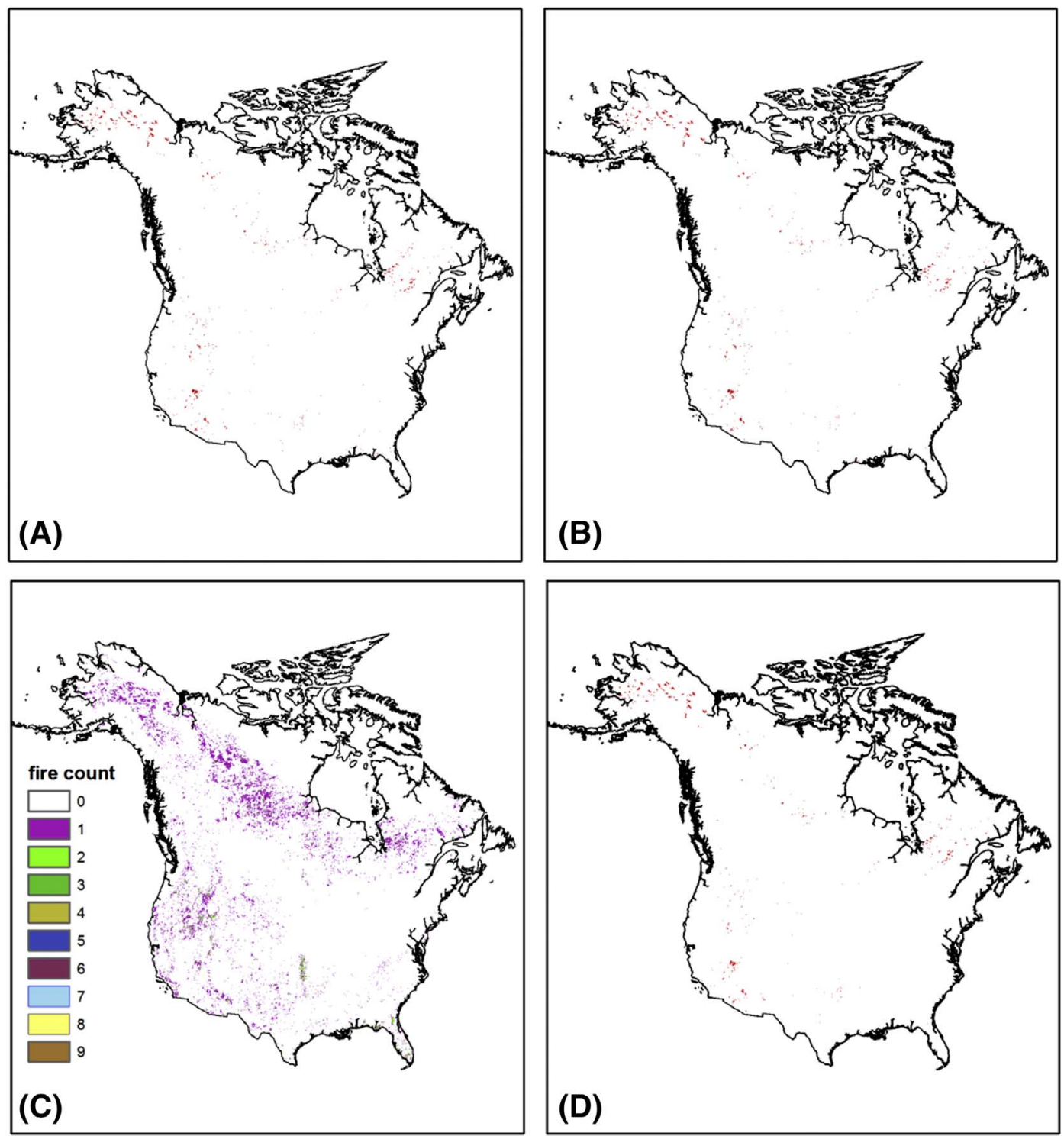

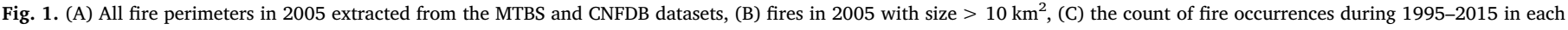
pixel, and (D) the selected fire pixels in 2005 with only one fire occurrence during 1995-2015.

vegetation dynamics. For example, studies in boreal regions indicated that the recovery time of boreal forest greenness varies between 5 and 9 years in North America (Goetz et al., 2006; Hicke et al., 2003; Jin et al., 2012), and over 13 years in Central Siberia (Cuevas-Gonzáles et al., 2009). Although the recovery of vegetation structure (such as leaf area index and tree height) has been examined by using remote sensing approaches (e.g. Magnussen and Wulder, 2012; McMichael et al., 2004; McCarley et al., 2017), more satellite-based studies have been focused on the spectral recovery of vegetation greenness (such as Normalized Difference Vegetation Index, NDVI and Enhanced Vegetation Index, EVI) (Goetz et al., 2007). Both high-resolution and coarse-resolution remote-sensing studies identified vegetation species, climate, fire severity, topography, and human management as critical factors in affecting the post-fire vegetation recovery trajectories (e.g. AlcarazSegura et al., 2010; Chu and Guo, 2013; Meng et al., 2015; White et al., 1996; Zhao et al., 2016).

Large-scale vegetation recovery studies (e.g. Goetz et al., 2006; Jin et al., 2012) often use ecoregions as basic ecological unit because different ecoregions are associated with different fire regimes, vegetation species, and climate condition (Chuvieco et al., 2008). Stand-replacing fires characterized by high burn severity and long return interval are the major fire types in boreal forests in North America (Rogers et al., 2015), whereas the low-severity prescribed fires are more pervasive in Southeast United States (Mitchell et al., 2014). Spatial variations in fire regimes and vegetation types could result in distinct vegetation recovery trajectories. Quantifying post-fire vegetation recovery trajectories at the continental scale across ecoregions and climate zones are essential for better understanding fire effects on ecosystems, devising post-fire land management practices, and improving fire parameterization in Earth System Models (Bartels et al., 2016; Goetz et al., 2005; Randerson et al., 2006; Rogers et al., 2013).

In this study, we chose North America (including the United States and Canada) as our study domain to investigate post-fire recovery of vegetation greenness by using two national-level fire perimeter datasets and the Moderate Resolution Imaging Spectroradiometer (MODIS) NDVI. Over the past few decades, North America has experienced a significant increase in fire frequency and burned area in the context of climate warming and drying condition (Dennison et al., 2014; Kasischke and Turetsky, 2006; Stocks et al., 2002; Westerling et al., 2006; Yang et al., 2015b). Frequent fire activities and large spatial variation of fire regimes make North America a valuable natural laboratory to investigate the post-fire vegetation recovery. Objectives of 
this study is threefold: (1) to quantify fire effect on vegetation greenness at a continental scale in ten post-fire years; (2) to examine the impacts of vegetation type and fire severity on post-fire vegetation greenness dynamics; and (3) to discuss future directions to improve vegetationfire models.

\section{Methods and datasets}

\subsection{Fire perimeters and fire pixels}

Time series of fire perimeters were obtained from two national-level datasets: The Monitoring Trends in Burn Severity (MTBS) in the United States (continental US and Alaska) and the Canadian National Fire Database (CNFDB) in Canada. MTBS is "a multi-year project designed to consistently map the burn severity and perimeters of fires across all the lands of the United States from 1984 and beyond" (http://www.mtbs. gov/). MTBS fire perimeters were created by the delineation of Landsatderived dNBR images (Eidenshink et al., 2007). CNFDB is a collection of fire perimeters and locations from multiple Canadian fire management agencies (Canadian Forest Service, 2015). The earliest fire records in the CNFDB can date back to the early 20th century. Both the original MTBS and CNFDB fire perimeters are in vector format.

Five steps were applied to extract fire pixels burned in 2005 from the MTBS and CNFDB fire perimeters. Pixels with more than one fire event in the period of 1995-2015 were excluded. Step 1: MTBS and CNFDB fire perimeters were registered to Albers conic equal-area projection and merged together. Fire perimeters in 2005 were selected from the merged dataset (Fig. 1A). Step 2: Fires with the size $<10 \mathrm{~km}^{2}$ were excluded (Fig. 1B) since small fires were associated with large edge-to-area ratio and could be composed of burned and unburned fire pixels when converted to raster format (Cuevas-Gonzáles et al., 2009). Step 3: Fire perimeters with the size $>10 \mathrm{~km}^{2}$ were converted to raster format at a spatial resolution of $1 \mathrm{~km}$. Fire pixels in cropland were excluded. Step 4: Annual fire perimeters from 1995 to 2015 were extracted from the merged fire perimeter dataset, and then converted into raster format at a 1-km spatial resolution. The number of fire occurrences in every pixel was counted over the 21 years from 1995 to 2015 (Fig. 1C). Step 5: Fire pixels with more than one fire occurrence were excluded to rule out the repeated burn effects (Fig. 1D). We conducted the analysis and statistics of fire effect on vegetation greenness and post-fire recovery for the selected fire pixels in 2005 .

\subsection{Ecoregions}

Vegetation within the same ecoregion experiences similar climate and human conditions. Ecoregion (ER) was often used as the basic ecological unit to investigate fire effect on ecosystems (e.g. Goetz et al., 2006; Hicke et al., 2003; Jin et al., 2012). In this study, we investigated fire effect over ecoregions delineated by Olson et al. (2001). Ecoregions with > 50 qualified fire pixels in 2005 were chosen to ensure the sample size large enough for relative accurate statistics. Based on this criterion, 39 ecoregions were finally chosen in the boreal and temperate North America (Fig. 2). The numbers of qualified fire pixels in these ecoregions are illustrated in Fig. 3. Table S1 lists the percentages of four vegetation types in the qualified fire pixels, 30-year average temperature and precipitation during 1981-2010, and centroid latitudes of the ecoregions. The average climate condition was estimated based on CRU TS v3.22 climate dataset. The ecoregions were further separated into 21 high-latitude ecoregions (centroid latitude $>45^{\circ} \mathrm{N}$ ) and 18 mid-latitude ecoregions (centroid latitude $<45^{\circ} \mathrm{N}$ ). The high-latitude ecoregions include ER1-ER19, ER21, and ER23, and the mid-latitude ecoregions include ER20, ER22, and ER24-ER39.

\subsection{MODIS products}

In this study, post-fire vegetation greenness was represented by
MODIS NDVI (MOD13A3 version 6) (Huete et al., 2002), which is available from February 2000 to present. Annual NDVI from 2001 to 2015 were retrieved by averaging monthly NDVI data. Pre-fire vegetation type in 2004 was acquired from MCD12Q1 version 5.1 (Friedl et al., 2010) by using the classification of Plant Functional Type (PFT) scheme. We examined fire effects on four vegetation types, including needleleaf trees, broadleaf trees, shrub, and grass. Fig. 3 shows the numbers of the qualified fire pixels for the four vegetation types in each ecoregion. Vegetation types with $>50$ fire pixels in one ecoregion (colored dots in Fig. 3) were included in the biome-level analysis.

8-Day composite surface reflectance product (MCD43B3 version 5) (Vermote et al., 2002) was used to estimate the differenced Normalized Burn Ratio (dNBR). Burning dates of each qualified fire pixels were extracted from MOD14A2 active fire products version 6 (Giglio et al., 2003). However, a small fraction of fire pixels in 2005 converted from MTBS and CNFDB is still unable to be covered by this active fire product. For these pixels, the same burning dates as their nearest pixels were assigned.

Annual Vegetation Continuous Field (VCF, MOD44B) was constructed by a regression tree algorithm (Hansen et al., 2002), which was designed to represent ground cover as a coverages of trees, herbaceous vegetation, and open ground (Carroll et al., 2010; Hansen et al., 2002, 2003). The continuous vegetation cover maps are useful to identify land areas experiencing vegetation changes induced by fire disturbances (Carroll et al., 2010). Fractional tree cover was estimated based on the amount of skylight intercepted by tree canopies higher than $5 \mathrm{~m}$, while plant lower than $5 \mathrm{~m}$ in height (such as grass, shrub, and tree seedling) was assumed to be non-tree vegetation.

All these MODIS products were originally in Hierarchical Data format (HDF) and Sinusoidal projection at the spatial resolutions of $250 \mathrm{~m}, 500 \mathrm{~m}$ or $1 \mathrm{~km}$. To be compatible with fire pixel developed in Section 2.1, these MODIS products were converted to Albers conic equal-area projection, and resampled to a spatial resolution of $1 \mathrm{~km}$.

\subsection{Fire severity index}

dNBR is sensitive to the loss of vegetation and landscape charring (Rogers et al., 2015), which is calculated by the reflectance in the nearinfrared band (NIR) and shortwave-infrared band (SWIR). dNBR was widely applied as one fire severity index in West US, boreal North America, and other regions of the world (e.g. Jin et al., 2012; Lentile et al., 2006; Loboda et al., 2007; Rogers et al., 2015; Veraverbeke et al., 2010). Many previous studies (e.g. Hall et al., 2008; Wimberly and Reilly, 2007) suggested the strong correlation between satellite-based dNBR and field-observed Composite Burn Index (CBI) (Key and Benson, 2006). dNBR in the study was computed by white-sky albedos in band 2 and band 7 from the MCD43B3 surface reflectance,

$$
\begin{aligned}
\mathrm{dNBR}= & N B R_{\text {pre-fire }}-N B R_{\text {post-fire }}=\left(\frac{\rho_{\text {NIR }}-\rho_{\text {SWIR }}}{\rho_{\text {NIR }}+\rho_{\text {SWIR }}}\right)_{\text {pre-fire }} \\
& -\left(\frac{\rho_{\text {NIR }}-\rho_{\text {SWIR }}}{\rho_{\text {NIR }}+\rho_{\text {SWIR }}}\right)_{\text {post-fire }}
\end{aligned}
$$

Pre-fire and post-fire periods here refer to the 8-day periods immediately before and after the date of fire occurrence. It should be noted that surface reflectance data may not be available when heavy cloud exists. Thus, dNBR was not calculated when surface reflectance data is missing. dNBR of the qualified pixels burned in 2005 is illustrated in Fig. S1.

At a large scale, dNBR was reported to have limited capacity in representing fire severity (e.g. Eidenshink et al., 2007; Kolden et al., 2015; Lentile et al., 2009; Miller and Thode, 2007). Therefore, we used an alternative index, the changed tree coverage (dTree), as a metrics of regional fire severity index for needle trees and broadleaf trees. This index was used previously as a proxy of regional fire severity in boreal 


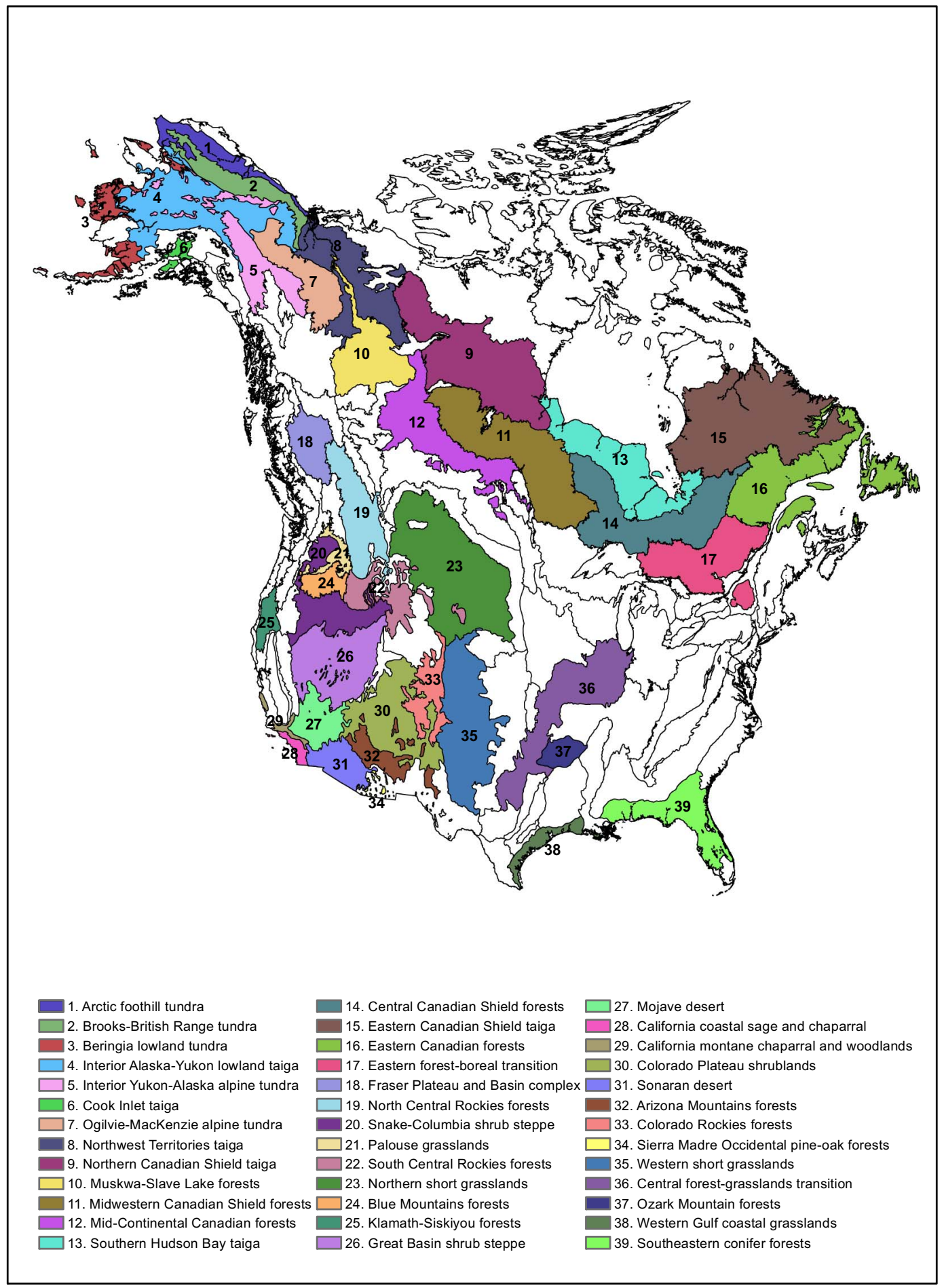

Fig. 2. Olson's ecoregions used in this study. All the 39 chosen ecoregions include at least $501-\mathrm{km}$ fire pixels.

North America and Eurasia (Rogers et al., 2015). In this study, dTree was calculated as,

$\mathrm{dTree}=\left(\right.$ fTree $_{\text {pre-fire }}-$ fTree $\left._{\text {post-fire }}\right) \times 100 \%$

where $f$ Tree is the fractional tree coverage from the MOD44B products; the pre-fire and post-fire periods in this equation refer to the year before and the year after fire occurrence (i.e., 2004 and 2006), respectively. Regional dTree was computed by averaging the dTree of the fire pixels (Fig. S2).

\subsection{Fire effect on NDVI}

Post-fire recovery is defined as the ecological processes to revert to the pre-fire or unburned functional and structural status. In this study fire effects specifically refer to the fire-induced changes in vegetation greenness. Two methods have been implemented previously to study fire effects on vegetation attributes and the post-fire vegetation recovery, which are named here as "comparison with pre-fire condition" and "comparison with unburned plots", respectively. For the first method, post-fire vegetation status was compared with that in the prefire period. The temporal differences were calculated to represent fire 


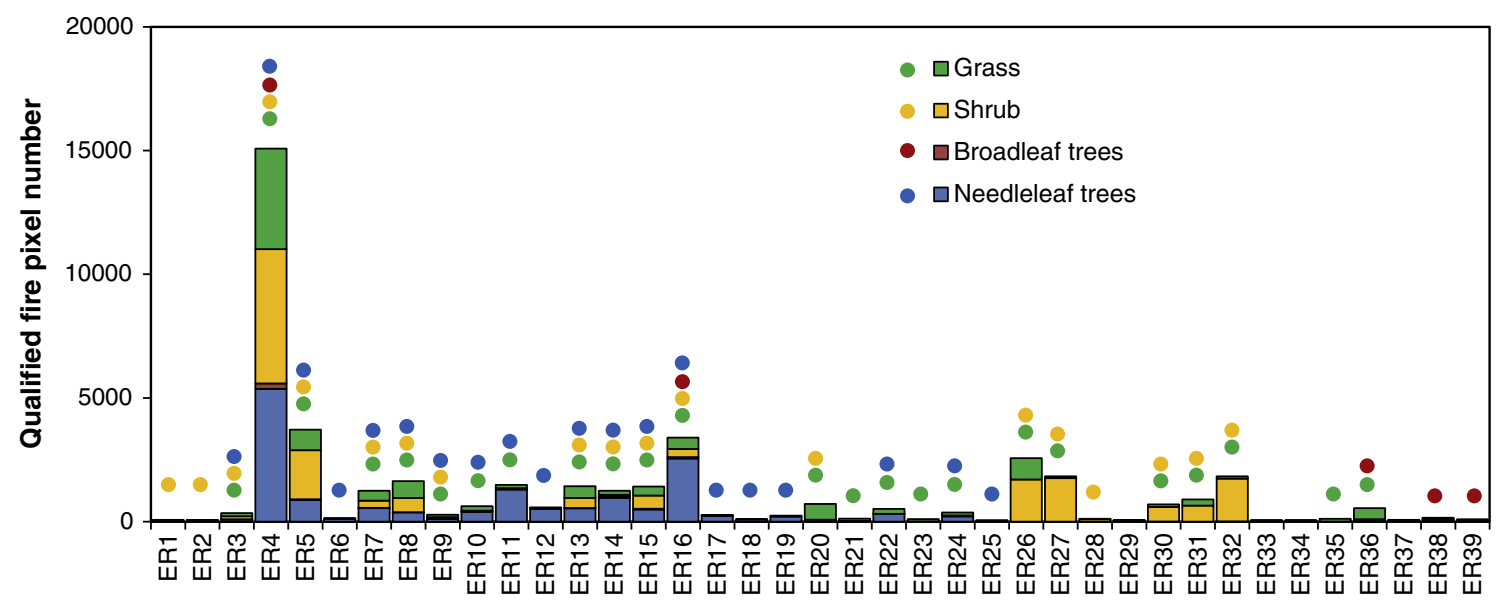

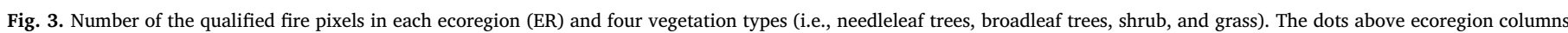

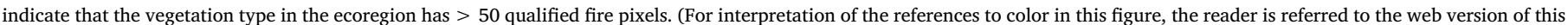
article.)

effect (e.g., Hicke et al., 2003; Meng et al., 2015). For the second method, vegetation attributes were compared between the burned fire scars and unburned plots. Spatial differences were analyzed to represent fire effect (e.g., Cuevas-Gonzáles et al., 2009; Goetz et al., 2006). In this study, we quantified fire effect on NDVI by using the method of "comparison with unburned plots". We also calculated fire effect on NDVI by the method of "comparison with pre-fire condition" but only for the purpose of evaluating the uncertainties caused by the different retrieval methods.

For the method of "comparison with unburned plots", we developed a new algorithm by comparing the burned pixel with surrounding unburned pixels. The effective unburned pixels (control pixels) were extracted from a square moving window based on three criteria: (1) identical vegetation type to the fire pixel, (2) similar topography as the fire pixel (i.e., elevation difference $<50 \mathrm{~m}$, and aspect difference $<$ $45^{\circ}$ ), and (3) no fire occurrence during 1995-2015. These criteria promise that the effective unburned pixels have similar environmental conditions as the fire pixel. The elevation and aspect were obtained from the HYDRO1K dataset (https://lta.cr.usgs.gov/HYDRO1K). Fig. S3 illustrates an example of the selection of the control pixels (in green color) in needleleaf forest in Alaska.

Fire effect on vegetation greenness $\left(\Delta \mathrm{NDVI}_{i}, i=2006 \ldots 2015\right)$ was estimated by the difference between the annual NDVI $\left(\mathrm{NDVI}_{i}\right)$ and the average annual NDVI of the effective unburned pixels $\left(\frac{\sum_{j=1}^{n} \mathrm{NDVI}_{i, j}}{n}\right)$,

$\Delta \mathrm{NDVI}_{i}=\mathrm{NDVI}_{i}-\frac{\sum_{j=1}^{n} \mathrm{NDVI}_{i, j}}{n}$

where $j$ is the index of effective unburned pixels in the square window, and $n$ is the total number of the effective unburned pixels. For each pixel, we computed the 10 -year average $\Delta \mathrm{NDVI}_{i}$ in the post-fire period to represent the recovery of vegetation greenness. Additionally, we calculated the 3-year average $\Delta \mathrm{NDVI}_{i}$ during the 8th-10th post-fire years to represent the "unrecovered NDVI" (Díaz-Delgado et al., 2003).

Fractional NDVI recovery (fNDVI) is estimated by using the 3-year average NDVI during the 8 th-10th post-fire years and the average NDVI of the effective unburned pixels in the square window,

$$
\begin{aligned}
\mathrm{fNDVI}= & \left(\frac{\mathrm{NDVI}_{2013}+\mathrm{NDVI}_{2014}+\mathrm{NDVI}_{2015}}{3}\right) \\
& /\left(\frac{\sum_{j=1}^{n} \mathrm{NDVI}_{2013, j}+\sum_{j=1}^{n} \mathrm{NDVI}_{2014, j}+\sum_{j=1}^{n} \mathrm{NDVI}_{2015, j}}{3 n}\right)
\end{aligned}
$$

The threshold of 0.95 was set to identify whether the post-fire NDVI recovered to unburned status.
We conducted a sensitivity test to evaluate the influence of the sizes of moving window on the results, including $50 \times 50$ pixels, $100 \times 100$ pixels, $150 \times 150$ pixels, and $200 \times 200$ pixels. Results showed that, except for ER18 and ER22, the estimated post-fire NDVI changes and recovery trajectories were relatively similar for the four window sizes (Fig. S4). Therefore, we only used the results derived from the window size of $100 \times 100$ pixels for further analysis.

We quantified the changing rate of $\Delta \mathrm{NDVI}_{i}$ time series in the 10 post-fire years by the rank-based, non-parametric Mann-Kendall Test and Sen's slope ( $\rho$, unit NDVI $\mathrm{yr}^{-1}$ ) as suggested by Alcaraz-Segura et al., 2010. Recovery trend is assumed to be significant when $\rho$ is positive and p-value $<0.05$.

For the method of "comparison with pre-fire condition", annual NDVI between 2001 and 2004 was averaged to represent the mean prefire vegetation greenness. Fire effect on vegetation greenness $\left(\Delta \mathrm{NDVI}_{i}, i=2006 \ldots 2015\right)$ was estimated by the temporal difference between annual NDVI in the post-fire year $\left(\mathrm{NDVI}_{i}\right)$ and the average NDVI in the pre-fire period.

$$
\begin{aligned}
\Delta \mathrm{NDVI}_{i}= & \mathrm{NDVI}_{i}-\mathrm{NDVI}_{\text {pre-fire }}=\mathrm{NDVI}_{i} \\
& -\frac{\mathrm{NDVI}_{2001}+\mathrm{NDVI}_{2002}+\mathrm{NDVI}_{2003}+\mathrm{NDVI}_{2004}}{4}
\end{aligned}
$$

\subsection{Analysis of fire severity impact on post-fire NDVI recovery}

We performed two-level analyses to examine the impact of fire severity on post-fire NDVI recovery over different fire pixels and over different ecoregions, respectively. Our hypothesis is that the variations of post-fire recovery can be explained by fire severity among fire pixels and over ecoregions. To evaluate the impact of fire severity on vegetation recovery over different pixels, the "unrecovered NDVI" was fitted against pixel dNBR in the same ecoregion for each of the examined vegetation types. The estimated regression coefficient was regarded as the sensitivity of vegetation greenness recovery to fire severity. To examine the impact of fire severity on vegetation recovery at the regional level, we fitted the "unrecovered NDVI" in each ecoregion against the regional dTree by using regression analysis for needleleaf trees and broadleaf trees, respectively.

\section{Results}

\subsection{Post-fire NDVI}

During 2006-2015, 10-year average $\Delta$ NDVI shows a large reduction $(\Delta$ NDVI $<-0.1)$ in $23.1 \%(9 / 39)$ of the ecoregions, a medium 

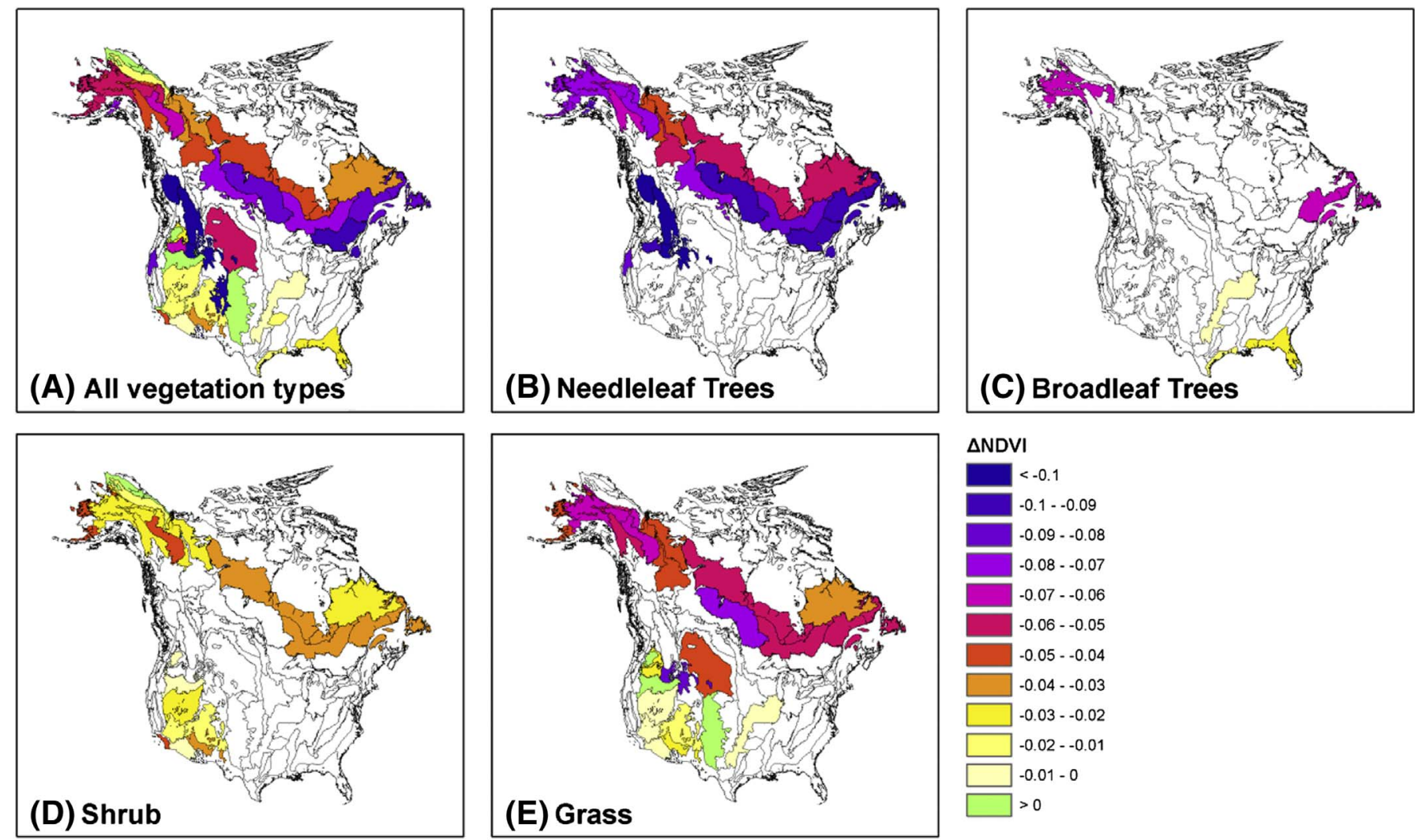

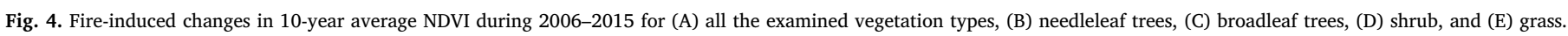

reduction $(-0.1<\Delta$ NDVI $<-0.05)$ in $30.8 \%(12 / 39)$ of the ecoregions, a small reduction $(-0.05<\Delta \mathrm{NDVI}<0)$ in $41 \%(16 / 39)$ of the ecoregions, and an increase $(\Delta \mathrm{NDVI}>0)$ in $5.1 \%(2 / 39)$ of the ecoregions (Fig. 4A). The largest reduction is in ER18 $(\Delta \mathrm{NDVI}=-0.14)$. 10-year average $\Delta$ NDVI during $2006-2015$ is $-0.071 \pm 0.038$ (avg. \pm 1 std. dev., same hereafter) in the 21 highlatitude ecoregions and $-0.038 \pm 0.041$ in the 18 mid-latitude ecoregions, indicating the larger fire effect on vegetation greenness in the high latitudes.

Needleleaf trees are associated with large NDVI reduction in $45 \%$ $(9 / 20)$ of the examined ecoregions and medium NDVI reduction in $55 \%$ $(11 / 20)$ of the examined ecoregions (Fig. 4B). For broadleaf trees, $40 \%$ $(2 / 5)$ of the examined ecoregions have medium reduction and $60 \%(3 /$ 5) of the examined ecoregions show a small reduction (Fig. 4C). For shrub, $21 \%(4 / 19)$ of the examined ecoregions have medium NDVI reduction, $73.7 \%(14 / 19)$ of the examined ecoregions have small NDVI reduction, and $5.3 \%(1 / 19)$ of the examined ecoregions have increased NDVI (Fig. 4D). Post-fire grass has medium NDVI reduction in $45.9 \%$ $(11 / 24)$ of the examined ecoregions, low NDVI reduction in $50 \%$ (12/ $24)$ of the examined ecoregions, and increased NDVI in $4.2 \%(1 / 24)$ of the examined ecoregions (Fig. 4E). As shown in Table 1, $\Delta$ NDVI for needleleaf trees is mainly in large and medium reduction categories, $\Delta$ NDVI for broadleaf trees and shrub are mainly in small reduction

Table 1

The percentages of the examined ecoregions in different $\Delta$ NDVI categories.

\begin{tabular}{lllll}
\hline & $\begin{array}{l}\text { Large } \\
\text { reduction }\end{array}$ & $\begin{array}{l}\text { Medium } \\
\text { reduction }\end{array}$ & $\begin{array}{l}\text { Small } \\
\text { reduction }\end{array}$ & Increase \\
\hline All vegetation & $23.1 \%$ & $30.8 \%$ & $41.0 \%$ & $5.1 \%$ \\
Needleleaf trees & $45 \%$ & $55 \%$ & $0 \%$ & $0 \%$ \\
Broadleaf trees & $0 \%$ & $40 \%$ & $60 \%$ & $0 \%$ \\
Shrub & $0 \%$ & $21.0 \%$ & $73.7 \%$ & $5.3 \%$ \\
Grass & $0 \%$ & $45.8 \%$ & $50.0 \%$ & $4.2 \%$ \\
\hline
\end{tabular}

category, while $\triangle$ NDVI for grass is mainly in medium and small reduction categories. The results show fire effects are stronger on needleleaf trees than on the other vegetation types.

In the 10 -year post-fire period, $\triangle$ NDVI increasing rate $(\rho)$ is significant in 48.7\% (19/39) of the ecoregions, with the largest $\rho$ in ER12

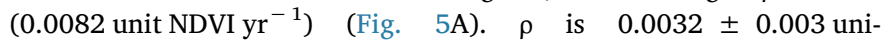

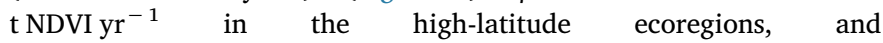
$0.0012 \pm 0.0023$ unit NDVI $\mathrm{yr}^{-1}$ in the mid-latitude ecoregions. For needleleaf trees, $\rho$ is $0.0036 \pm 0.0029$ unit NDVI yr ${ }^{-1}$ among the 20 examined ecoregions, and significant in $70 \%(14 / 20)$ of the ecoregions. For broadleaf trees, $\rho$ is $0 \pm 0.0029$ unit NDVI $\mathrm{yr}^{-1}$, and the significant $\rho$ was only found in the two high-latitude ecoregions. For shrub, $\rho$ is $0.0022 \pm 0.0019$ unit NDVI yr $^{-1}$ in the 19 examined ecoregions, $0.0029 \pm 0.0019$ unit NDVI $\mathrm{yr}^{-1}$ in the 12 examined high-latitude ecoregions, and $0.0008 \pm 0.0012$ unit NDVI yr $^{-1}$ in the 7 examined mid-latitude ecoregions. For grass, $\rho$ is $0.0029 \pm 0.0021$ uni-

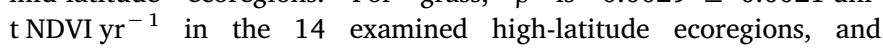
$0.0008 \pm 0.0009$ unit NDVI $\mathrm{yr}^{-1}$ in the 10 examined mid-latitude ecoregions. In general, the post-fire NDVI increase is more rapid in the high-latitude ecoregions, and needleleaf trees have the most rapid postfire NDVI increase of all the examined vegetation types.

Fig. 6 shows the average fractional recovery of NDVI between the 8th and 10th post-fire years. During 2013-2015, fNDVI is higher than 0.95 in $20.5 \%(8 / 39)$ of the ecoregions. $4.8 \%(1 / 21)$ of the high-latitude ecoregions have fNDVI higher than 0.95 , while $38.9 \%(7 / 18)$ of the mid-latitude ecoregions have fNDVI higher than 0.95 , indicating that most ecoregions (especially the high-latitude ecoregions) have not recovered to unburned status within 10 years. For needleleaf trees, fNDVI in none of the 20 examined ecoregions is larger than 0.95 . Thus, the recovery time for needleleaf trees could be longer than 10 years. For broadleaf trees, fNDVI is lower than 0.95 in the two high-latitude ecoregions, but higher than 0.95 in the three mid-latitude ecoregions. For shrub, fNDVI in $15.8 \%$ (3/19) of the examined ecoregions is higher than 0.95 . For grass, fNDVI in $25 \%(6 / 24)$ of the examined ecoregions 

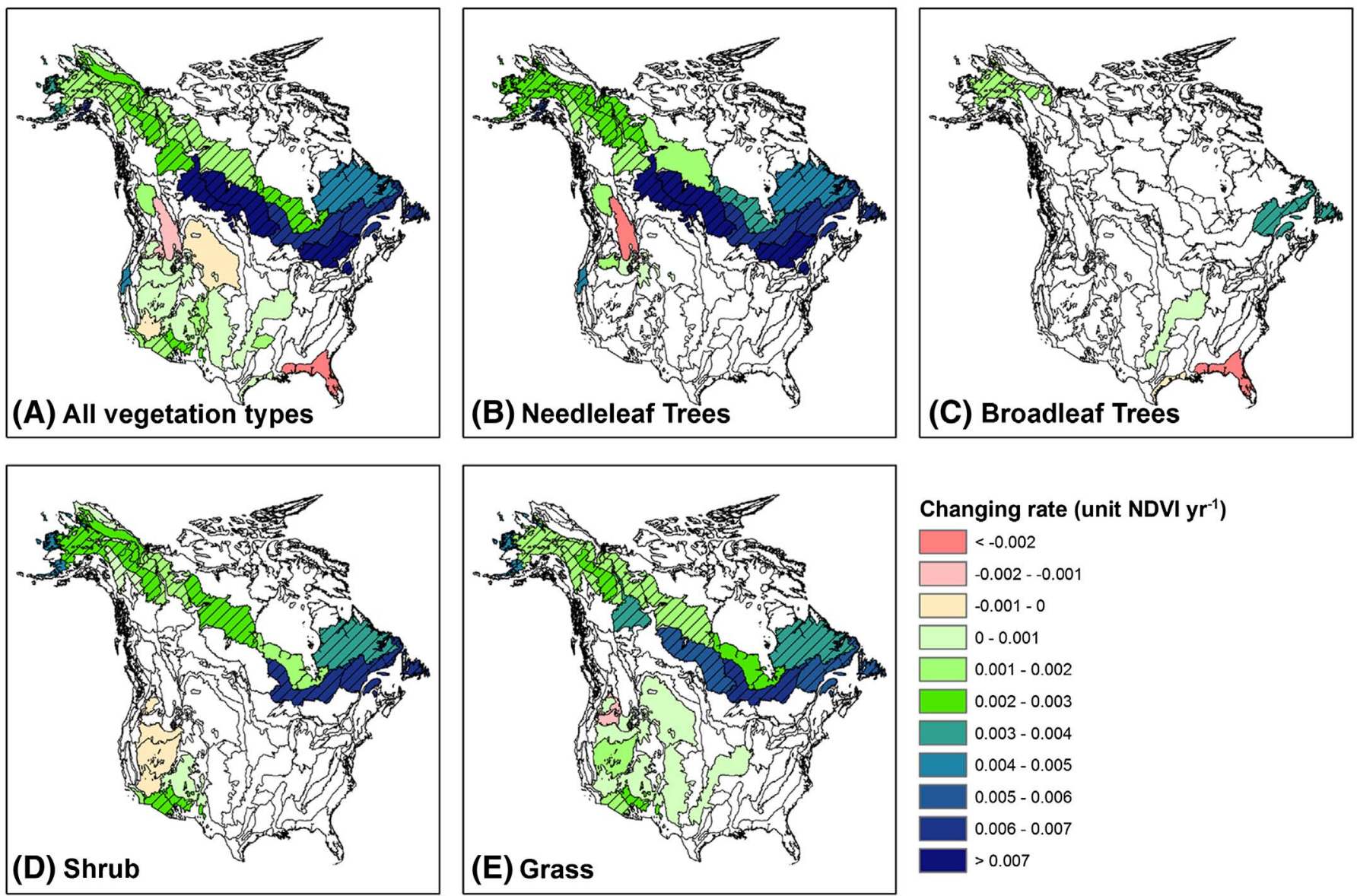

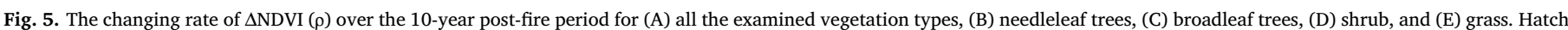
lines indicate a significant changing trend at the $95 \%$ confidence interval.

is higher than 0.95 .

\subsection{Impact of vegetation type on post-fire NDVI}

Post-fire inter-annual $\triangle$ NDVI variations were compared among different vegetation types for 10 ecoregions. Each ecoregion has at least three vegetation types with $>50$ qualified fire pixels. As shown in Fig. 7, fire effect is the strongest on needleleaf trees in 9 of the 10 examined ecoregions, while fire effect is the least on shrub in all the 10 examined ecoregions. For the two ecoregions including four vegetation types (i.e., ER4 and ER16), fire effect on vegetation types can be ranked as: needleleaf trees $>$ grass $>$ broadleaf trees $>$ shrub. These results suggest that the recovery of vegetation greenness is related to vegetation type, with stronger fire effect on needleleaf trees and lower fire effect on broadleaf trees and shrub. Although the $\Delta$ NDVI increasing rate for needleleaf trees is faster than that of other vegetation types, needleleaf trees still need a longer recovery time due to the larger NDVI reduction after fire (see the conceptual diagram in Fig. S5).

The 10-year average $\triangle$ NDVI at regional level was fitted against the percentages of vegetation types in the 39 ecoregions (Fig. 8). It is found that the regional $\triangle$ NDVI is significantly related to the fractions of needleleaf trees, shrub, and grass ( $p$-value $<0.05$ ). The area percentage of needleleaf trees can explain $72 \%$ of the $\Delta$ NDVI variation among different ecoregions. As shown by Fig. 8A, 1\% increases in the area of needleleaf trees leads to a larger reduction of the 10-year average $\Delta$ NDVI by 0.0011 . On the contrary, the increase in the area percentages of shrub, grass, and broadleaf trees could result in less reduction in the post-fire NDVI. The percentage of broadleaf tree area can only explain $6 \%$ of the $\triangle$ NDVI variation over ecoregions. This is probably because broadleaf forests were not burned or only burned in a small area in most of the examined ecoregions in 2005. Another explanation for this phenomenon is the fast resprouting strategy of broadleaf trees to adapt to fire disturbance (Franklin et al., 2006; Keeley et al., 2011). This analysis suggests that vegetation composition is one factor accounting for the variations of fire effect among ecoregions.

\subsection{Impact of fire severity on post-fire NDVI recovery}

The sensitivity of NDVI recovery during the 8th-10th post-fire years to pixel burn severity was examined by the regression coefficient of the "unrecovered NDVI" against pixel dNBR (Fig. 9). For needleleaf trees, average regression coefficient is $-0.07 \pm 0.05$ unit NDVI per unit $\mathrm{dNBR}$ in all the 20 ecoregions. All the ecoregions have negative regression coefficient, and the coefficients are significant in $75 \%(15 / 20)$ of the ecoregions, suggesting that higher dNBR leads to larger NDVI reduction and longer fire effect. For shrub, $78.9 \%$ (15/19) of the ecoregions show significant correlation between NDVI recovery and dNBR. For grass, $66.7 \%(16 / 24)$ of the ecoregions show significant correlation between the NDVI recovery and dNBR. It can be concluded that fire severity is one important factor regulating the post-fire recovery during the 8th-10th post-fire years for needleleaf forests, shrub and grass. However, for broadleaf trees, the "unrecovery NDVI" during the 8th-10th post-fire years is not significantly related to dNBR in all the five examined ecoregions. This is probably due to the smaller fire effect on NDVI reduction, the faster post-fire resprouting, and shorter recovery time for broadleaf trees (Franklin et al., 2006).

Fig. 10 shows the influence of fire severity on vegetation recovery across different ecoregions, represented by the regression between the "unrecovered NDVI" and the regional average dTree. For needleleaf trees over the 20 examined ecoregions, the "unrecovered NDVI" is 

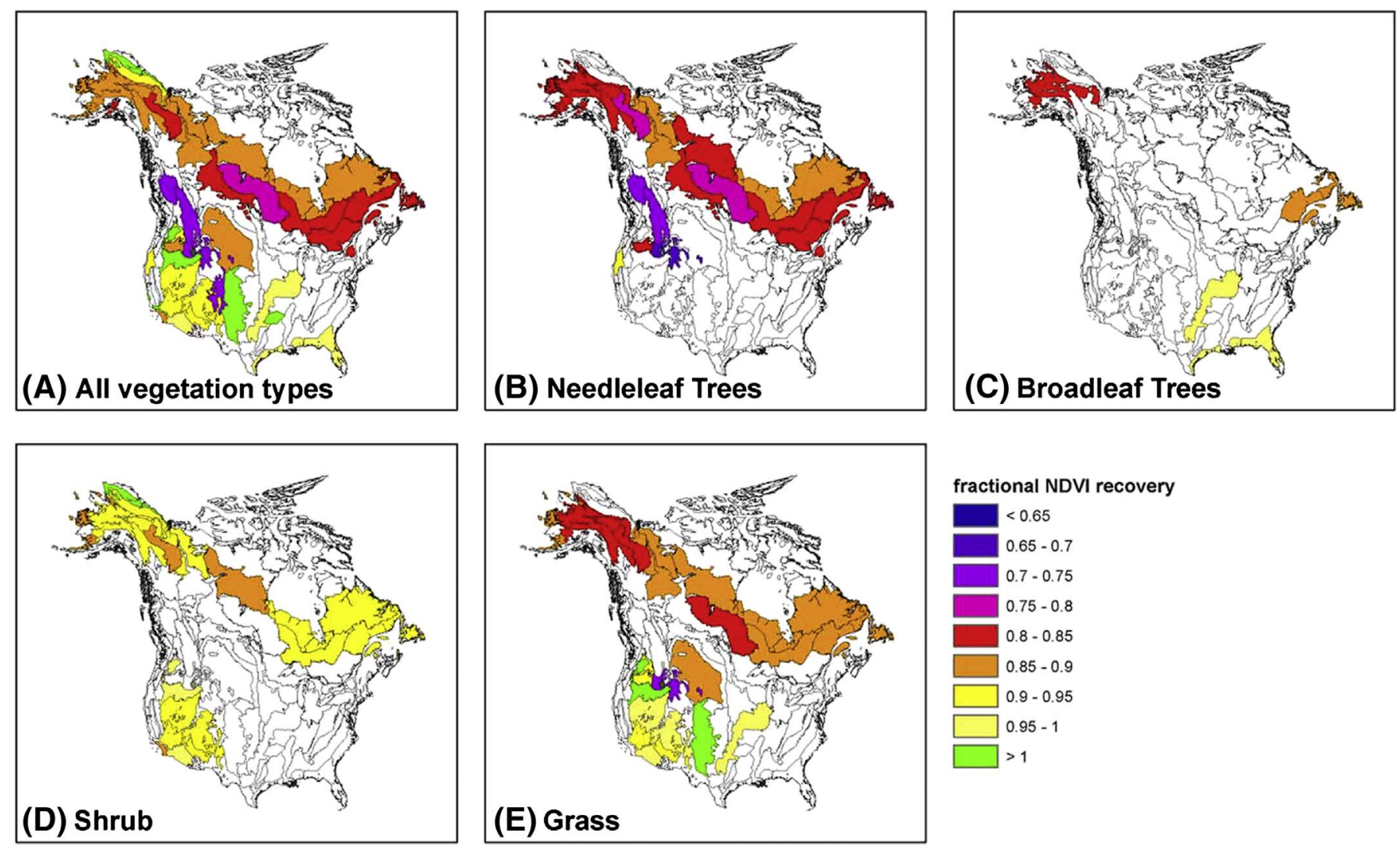

Fig. 6. Fractional NDVI recovery during 2013-2015 for (A) all the examined vegetation types, (B) needleleaf trees, (C) broadleaf trees, (D) shrub, and (E) grass.

significantly correlated with fire severity, and $48 \%$ of the regional variation of the "unrecovered NDVI" can be explained by dTree. For broadleaf trees over the 5 examined ecoregions, the spatial variation of the "unrecovered NDVI" is correlated to fire severity as well, and the correlation coefficient is significant at the $90 \%$ confidence interval. This result indicates that fire severity plays an important role in forest NDVI recovery over different ecoregions.

\section{Discussion}

\subsection{Factors controlling the spatial variation of the post-fire NDVI}

Post-fire changes in NDVI show distinct spatial variations and the fire effect on NDVI is generally larger in the high-latitude ecoregions than that in the mid-latitude ecoregions (Fig. 4A). The variations of fire effect on NDVI among ecoregions can be largely explained by the vegetation composition, especially the fraction of needleleaf trees. According to the comparison among different vegetation types, fire effect on NDVI is stronger for needleleaf trees, and lower for broadleaf trees and shrub (Fig. 7), indicating that vegetation type is an important factor determining fire effect. The finding of stronger fire effect on needleleaf trees is confirmed by previous studies based on the high-resolution satellite imageries and the aerial photo (Allen and Sorbel, 2008; Jin et al., 2012; Thompson and Spies, 2009). Vegetation types diverge in their fire-adaptive traits, such as resprouting, serotiny, and gemination (Keeley et al., 2011; Quinn and Keeley, 2006). Serotiny is the fireadaptive trait for many needleleaf trees in boreal North America, including black spruce (Picea mariana), jack pine (Pinus banksiana), etc. These species need high-severity fires to open the (semi-)serotinous cones and release seeds for regeneration. Low branches and other morphological characteristics are important for these species to promote high-intensity crown fires (Rogers et al., 2015). On the contrary, broadleaf trees and broadleaf shrub often burn in lower severity and sometimes act as barriers to spreading fire (Epting and Verbyla, 2005). Post-fire resprouting is a more popular fire-adaptive trait for broadleaf trees (Franklin et al., 2006; Keeley et al., 2011). Therefore, the variation of fire effect was explained by vegetation composition to a large extent.

The significant impact of fire severity on the recovery of post-fire vegetation greenness is confirmed by the field observations. For example, after the 1988 Yellowstone fires, vegetation coverage in 1992 over the severely burned area was about $50 \%$ of pre-fire level, while vegetation coverage in 1992 returned to pre-fire level over the lightly burned area (Turner et al., 2000, 2003). The significant impact of fire severity on the post-fire NDVI recovery found in this study is also consistent with other satellite-based studies in boreal (e.g. Chu et al., 2017; Jin et al., 2012; Johnstone and Chapin, 2006) and temperate region (Díaz-Delgado et al., 2003).

\subsection{Comparison of recovery time with other studies}

Previous studies showed large variations in the recovery time of boreal forests by using satellite observations. Hicke et al. (2003) reported that the recovery time of forest greenness was about 9 years in boreal North America; Goetz et al. (2006) found a relative shorter NDVI recovery time (5 years) in Canada; Jin et al. (2012) found that the summer EVI has recovered to within $90 \%-108 \%$ of prefire levels in 5-8 years after fire. Our results showed that the post-fire NDVI for boreal forests in North America needs a longer recovery time, which could be $>10$ years. The difference could be attributed to the different NDVI data source and fire events. First, Hicke et al. (2003) and Goetz et al. (2006) used 8-km Advanced Very High Resolution Radiometer (AVHRR) NDVI product, while we used 1-km MODIS product. The recovery time estimated by satellite-based vegetation indices is scaledependent (Hicke et al., 2003), and the aggregation of NDVI over 8-km pixel may lead to a faster recovery (Cuevas-Gonzáles et al., 2009). 
(A) ER3

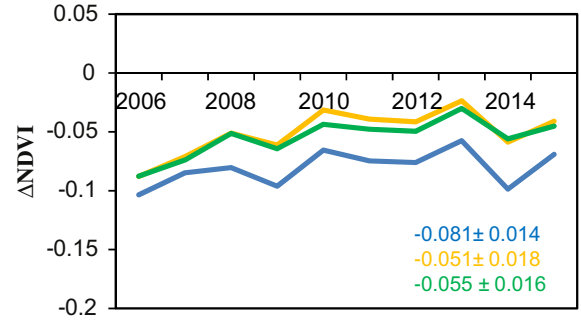

(D) ER7

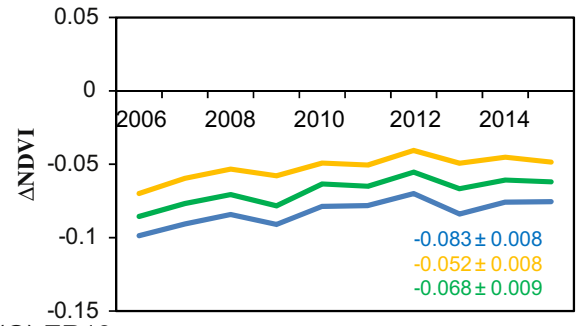

(G) ER13

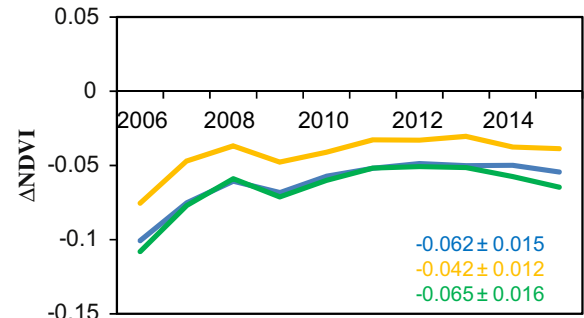

(J) ER16

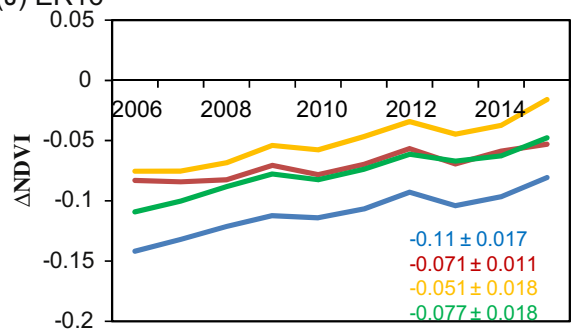

(B) ER4

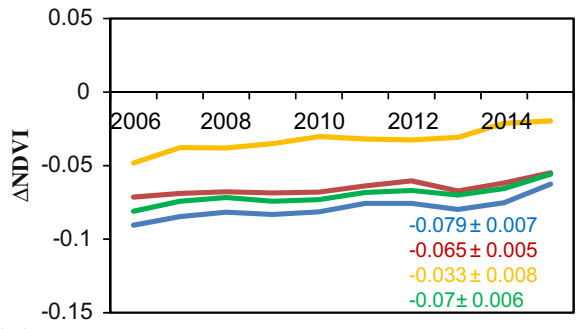

(E) ER8

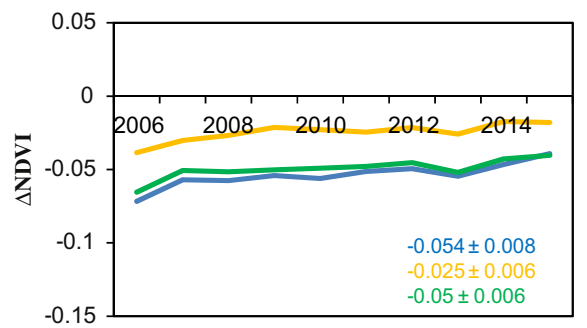

(H) ER14

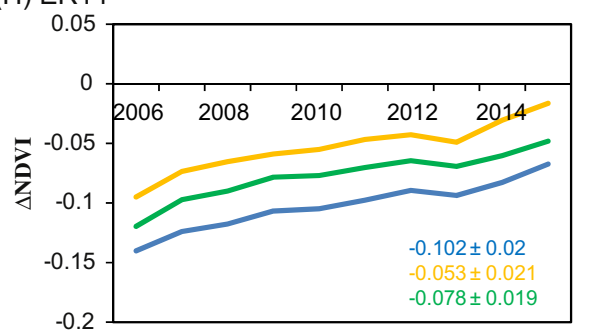

(C) ER5

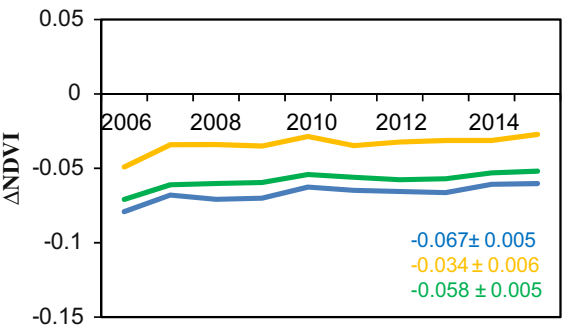

(F) ER9

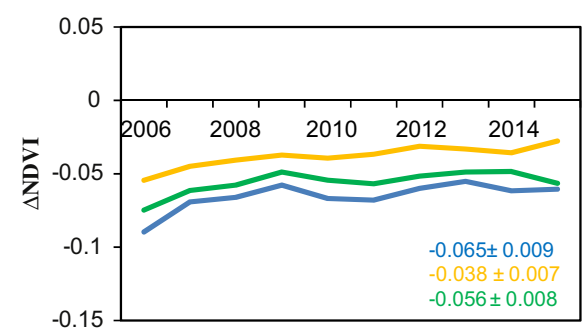

(I) ER15

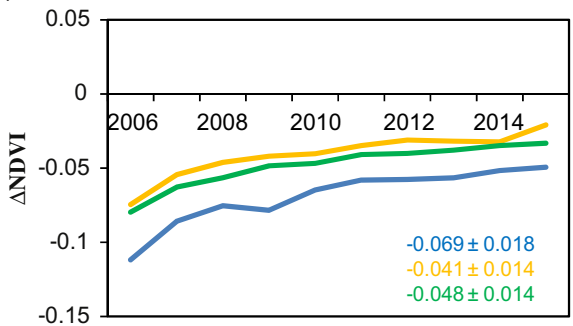

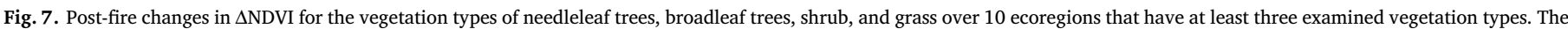

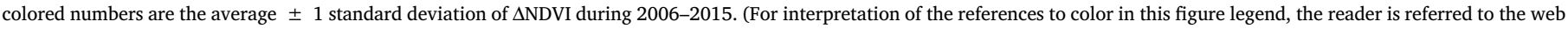
version of this article.)

Second, our study included all the large fires in 2005, while Goetz et al. (2006) selected the large fires in several ecoregions in three episodic years (1981, 1989 and 1995), and Hicke et al. (2003) focused on 61 fires with the size larger than $1000 \mathrm{~km}^{2}$ from 1980 to 1995 . Forest composition, fire severity, and post-fire environmental condition were different among these studies.

Our study showed that, by 8-10 years after fire, fractional NDVI recovery is still $<90 \%$ for boreal needleleaf trees in most of the ecoregions (Fig. 6B), indicating a larger fire effect than that estimated by Jin et al. (2012). This divergence could be partially attributed to the different study methods. Jin et al. (2012) investigated post-fire vegetation recovery by the method of "comparison with pre-fire condition", which is supposed to estimate a faster recovery than that estimated by the method of "comparison with unburned plots" (see Section 4.3). Additionally, vegetation greenness in Jin et al. (2012) was represented by EVI, which is sensitive to vegetation dynamics over the dense biomass area, such as Amazon forests (Huete et al., 2002), while we used NDVI, which is more sensitive to vegetation changes in lower biomass area and widely applied to investigate post-fire vegetation recovery (Yang et al., 2012). The difference in the vegetation recovery estimated by EVI and NDVI is still unclear and need to be evaluated in future studies.

In California, Meng et al. (2015) studied post-fire forest recovery by using Landsat-based imageries. Their results showed that the forest NDVI in the 5th post-fire year is still much lower than the pre-fire NDVI (Fig. 3 in Meng et al., 2015). In this study, we found that the NDVI at the 5 th post-fire year is 0.103 lower than NDVI of the unburned pixels for needleleaf trees in ER25 (California) which is similar as Meng et al. (2015).

\subsection{Uncertainties}

Uncertainties in this study mainly come from the MODIS vegetation greenness product and the study method. The standard MODIS greenness products were reported to contain artefacts of variations in sunsensor geometry (Morton et al., 2014). MODIS-based NDVI was assumed to be overestimated during the early post-fire period (Cheng et al., 2006). Thus, our study using MODIS products might underestimate fire effect to some extent. Landsat imageries and LiDAR datasets have been applied to evaluate post-fire vegetation dynamics and have higher accuracy in fire effect assessment especially for the fragmented landscape (e.g. Meng et al., 2015; Wulder et al., 2009). The comparison of the post-fire NDVI derived from MODIS datasets and other high-resolution remote sensing could be helpful to quantify the uncertainties caused by MODIS product and worthy a future 
(A)

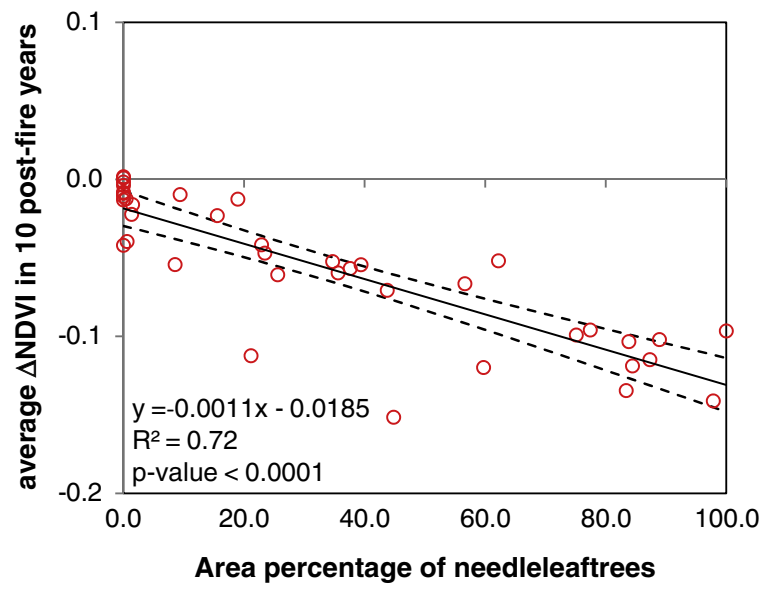

(C)

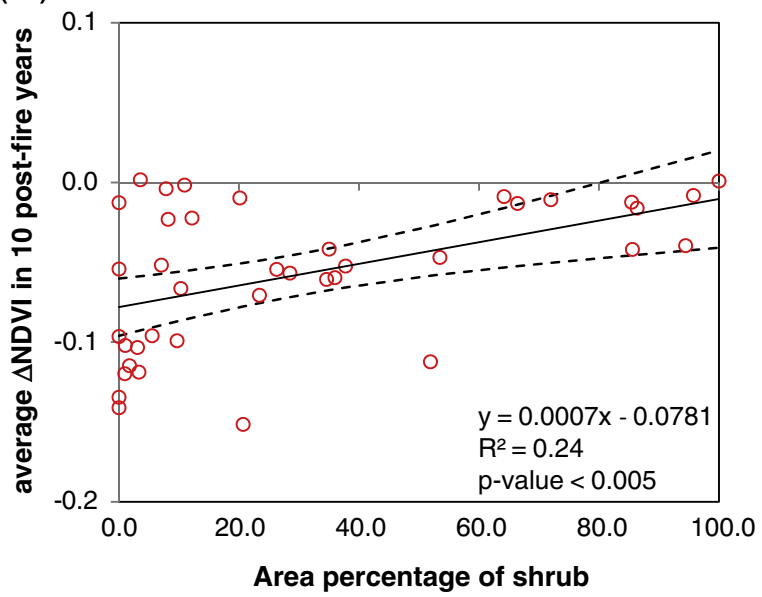

(B)

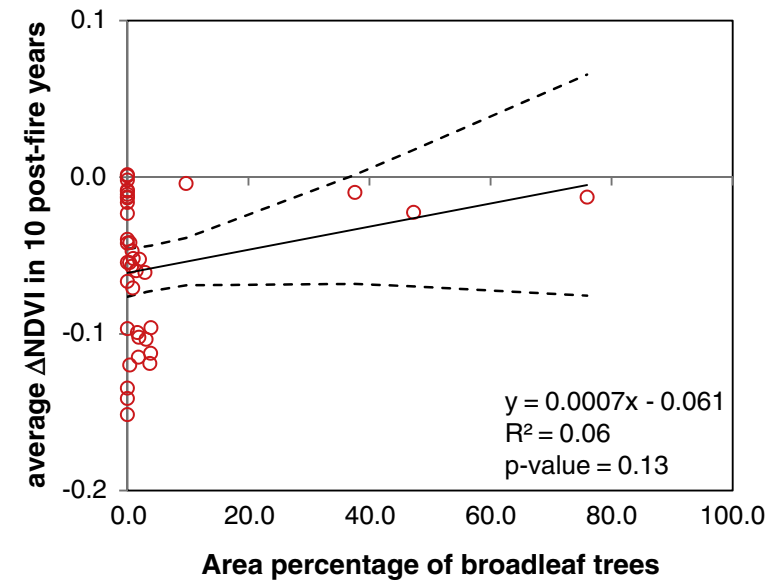

(D)

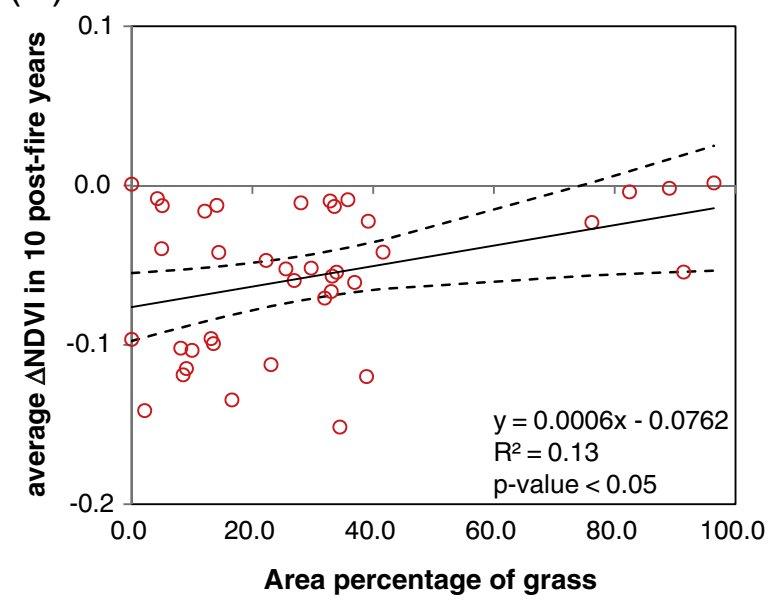

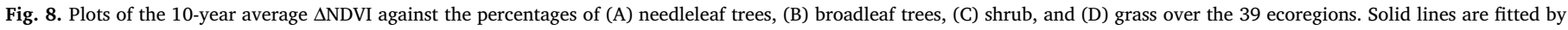
linear regression, and dashed lines represent the $95 \%$ confidence interval of the regression. p-Value is obtained by the F-test of the overall significance.

investigation. Additionally, vegetation greenness based on the MODIS reflectance after MultiAngle Implementation of Atmospheric Correction (MAIAC) (Lyapustin et al., 2011) may be helpful to acquire a more accurate estimate by filtering cloud contamination and the artefact of variation in sun-sensor geometry.

Fire effect on vegetation greenness estimated by "comparison with unburned plots" was compared with that estimated by "comparison with pre-fire condition" (Fig. S6). Although both methods are able to capture the post-fire NDVI recovery trend, the differences in the postfire NDVI trajectories are evident, indicating the existence of uncertainty in the study method. For all the selected fire pixels over the entire domain, the 10 -year average $\triangle$ NDVI is -0.05 estimated by "comparison with unburned plots" and -0.04 estimated by "comparison with pre-fire condition", indicating a larger fire effect estimated by "comparison with unburned plots". The average $\rho$ is 0.0023 unit NDVI $\mathrm{yr}^{-1}$ estimated by "comparison with unburned plots" and 0.003 unit NDVI yr ${ }^{-1}$ estimated by "comparison with pre-fire condition", indicating a slower recovery of post-fire NDVI by "comparison with unburned plots".

For the selection of surrounding effective unburned pixels (Section 2.5), we considered the similarity of vegetation type and topography. Nevertheless, disturbance history (such as logging, insect, and hurricane) is neglected due to the lack of continental-scale disturbance datasets, which may lead to uncertainties. For the method of "comparison with pre-fire condition", post-fire NDVI trajectory could be affected by multiple environmental factors in the post-fire period that stimulate vegetation growth, such as $\mathrm{CO}_{2}$ fertilization and nitrogen deposition. For the method of "comparison with unburned plots", the effects of climate variations, $\mathrm{CO}_{2}$ and nitrogen deposition on NDVI recovery were partially reduced, since both burned and the unburned fire pixels experienced environmental changes over the post-fire period. Therefore, the method of "comparison with pre-fire condition" estimated a faster post-fire NDVI recovery.

\subsection{Implications for fire model improvement}

This study provided large-scale evidences of the impact of fire severity on vegetation greenness recovery. In current vegetation-fire models, fire severity is usually represented by plant functional type (PFT)-specific parameters without spatial and temporal changes (e.g., Arora and Boer, 2005; Li et al., 2012). However, this assumption is not consistent with field measurements, which showed significant spatial variations of fire severity and biomass combustion completeness (van Leeuwen et al., 2014). For instance, combustion completeness for boreal forests could vary between $8 \%$ and $87 \%$ over different regions. The ill-represented fire severity and combustion completeness contributed to a large fraction of the bias in the simulated fuel combustion (van Leeuwen et al., 2014), fire emissions (Yang et al., 2015b), and climate conditions by Earth System Models (Li et al., 2017).

The parameterization of fire effect on vegetation could potentially be improved in the following aspects: 

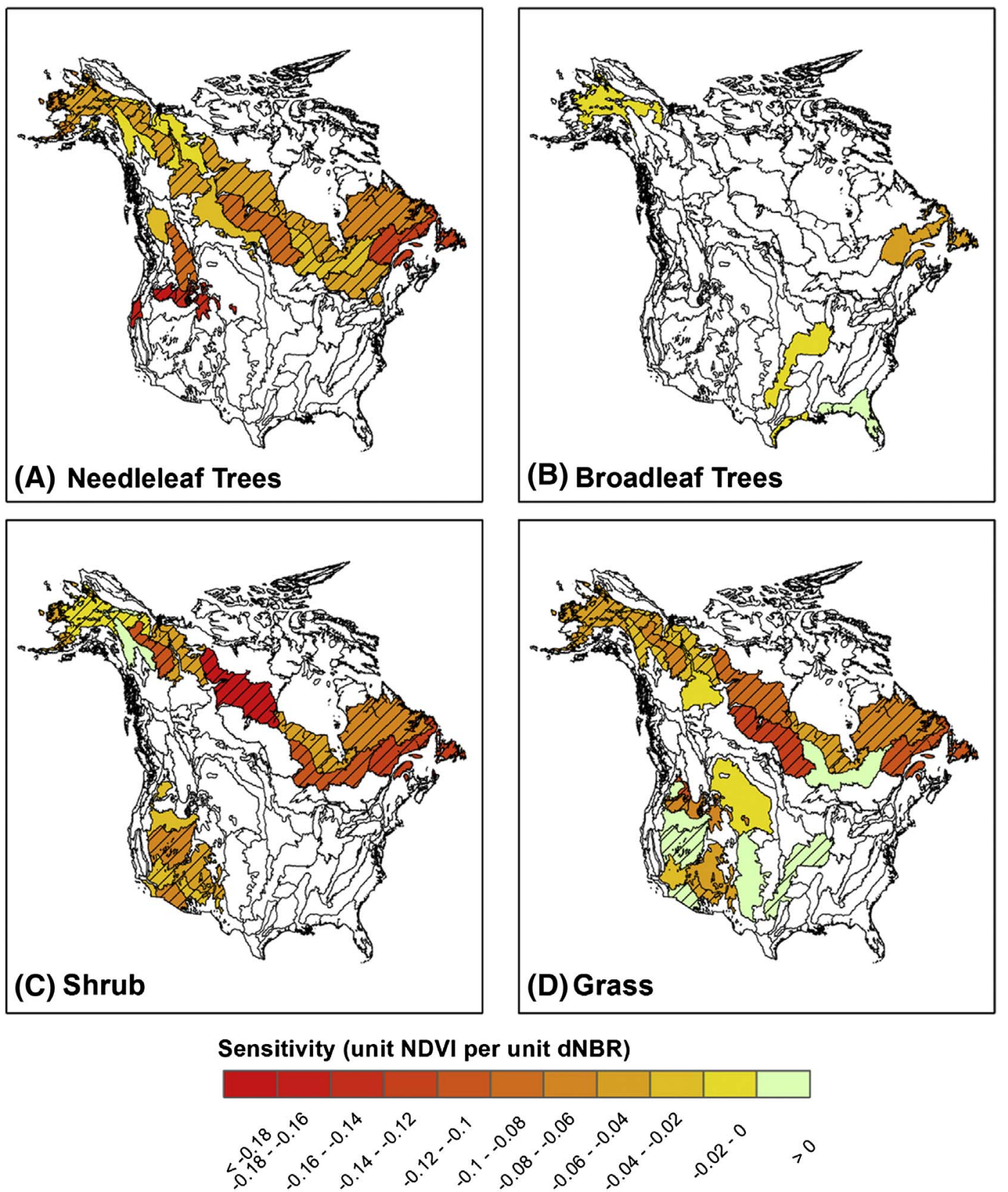

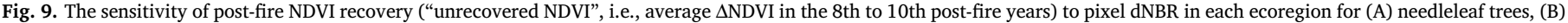
broadleaf trees, (C) shrub, and (D) grass. Hatch lines indicate that the sensitivity is significant at the $95 \%$ confidence interval.

(1) Fire severity. Fire severity is largely predictable by using vegetation species, topography, burning conditions, and fuel characteristics (Viedma et al., 2015). These factors ought to be explicitly parameterized to improve model simulations. In recent years, more sophisticated fire models, such as SPITFIRE (Thonicke et al., 2010) and LPJ-LMfire (Pfeiffer et al., 2013), simulated combustion completeness and fire mortality by considering fuel moisture, weather conditions, and vegetation fire-adaptive traits (e.g. bark thickness and canopy height). It is an improvement over previous fire models. However, bark thickness and canopy height in SPITFIRE and LPJLMfire were still represented by PFT-specific parameters without considering variations among different species. The recent developed global fuel data set using the Fuel Characteristic Classification System (Pettinari and Chuvieco, 2016) provided spatially-explicit fuelbed map, which can potentially be used to estimate canopy structure and fuel attributes and coupled into fire models to improve fire severity simulation.

(2) Postfire recovery. Post-fire vegetation recovery trajectories showed variations among fire pixels (e.g. Alcaraz-Segura et al., 2010; White et al., 1996; Zhao et al., 2016). Higher model spatial resolution could improve the accuracy in simulating post-fire vegetation dynamics. However, pixel-level simulation at $\sim 1 \mathrm{~km}$ resolution is not plausible for large-scale studies. For the coarse-resolution grid-level simulation, appropriate upscaling strategies are important. Vegetation dynamics models without age cohort structure, such as LPJ model (Sitch et al., 2003), simulated post-fire vegetation recovery by using the average of old vegetation and newly established vegetation. By contrast, gap-based vegetation dynamics models, such as CLM(ED) (Fisher et al., 2015), explicitly considered fire-induced age structure and simulated vegetation succession in the open spaces. Theoretically, gap-based vegetation models can better represent post-fire vegetation recovery for the partially burned grids 
(A) Needleleaf Trees

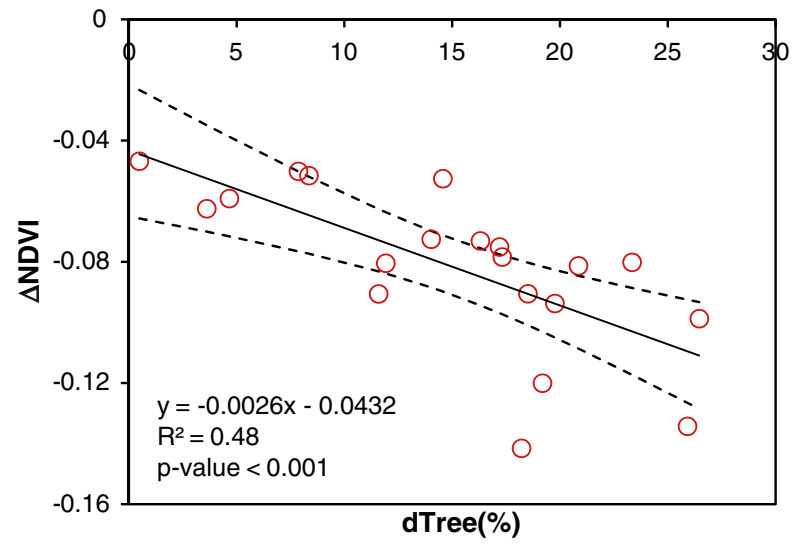

(B) Broadleaf Trees

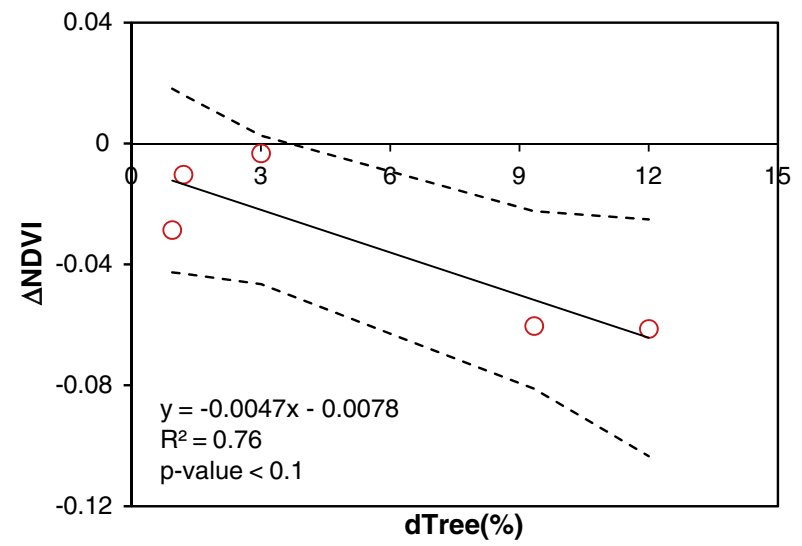

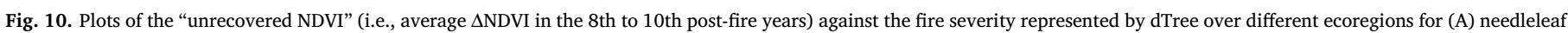

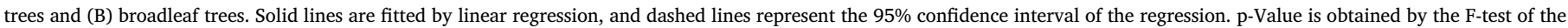
overall significance of linear regression.

than models without age cohort (Fisher et al., 2015). The ongoing effort of fire model intercomparison project (Hantson et al., 2016) is expected to give more specific answers about the advantage of gapbased models. Additionally, the consideration of post-fire regeneration strategies (such as resprouting and serotiny) may help improve the simulation of post-fire recovery.

(3) Remote sensing-based constrains. One notable advantage of remote sensing is to illustrate regional and global pictures of fire effect across various ecoregions and climate zones. Global burned fraction from satellite observations had been used as benchmark data set for evaluating global vegetation models (Kelley et al., 2013; Yang et al., 2014). We suggest that satellite-derived vegetation metrics should also be used for validating fire effect simulated by models. Besides vegetation greenness used in this study, other satellite-based vegetation parameters, such as solar-induced chlorophyll fluorescence (Joiner et al., 2014), leaf area index (McMichael et al., 2004), canopy height (Magnussen and Wulder, 2012), and vegetation fraction (Carroll et al., 2010), could reveal the postfire recovery of vegetation functional and structural properties. LANDSAT-based forest loss data (Hansen et al., 2013) could be further processed to retrieve the fire-induced tree mortality at a large scale (Krylov et al., 2014). These datasets would be beneficial to the parameterization of fire effects in vegetation-fire models and Earth System Models.

\section{Conclusions}

By using MODIS products and two national-level fire perimeter datasets, we evaluated fire effect on vegetation greenness in the early post-fire period at a continental scale. Fire effect on post-fire NDVI was found to be stronger for needleleaf trees than for other vegetation types. The high-latitude ecoregions were associated with larger reduction in vegetation greenness and longer NDVI recovery time than the mid-latitude ecoregions. Vegetation composition, especially the fraction of needleleaf trees, explains a large part of the spatial variations of fire effect on NDVI. Fire severity is an important factor regulating the spatial pattern of post-fire NDVI recovery over pixels and ecoregions. Furthermore, we found a longer NDVI recovery time for boreal forests than existing estimates, indicating a stronger fire effect on terrestrial ecosystems than previously thought. This study provides large-scale insight into the post-fire vegetation dynamics, which is pivotal to understand fire effects on terrestrial ecosystem dynamics and improve the parameterization of fire effect in the Earth System Models.

\section{Acknowledgements}

This work has been supported by National Key Research and Development Program of China (No. 2017YFA0604700), National Science Foundation Grants (1243232) and SKLURE Grant (SKLURE2017-1-6). We thank the anonymous reviewers and Editor E. Chuvieco for their valuable comments. Availability of data sets used in this study is described in Section 2.

\section{Appendix A. Supplementary data}

Supplementary data to this article can be found online at http://dx. doi.org/10.1016/j.rse.2017.07.022.

\section{References}

Alcaraz-Segura, D., Chuvieco, E., Epstein, H.E., Kasischke, E.S., Trishchenko, A., 2010. Debating the greening vs. browning of the North American boreal forest: differences between satellite datasets. Glob. Chang. Biol. 16, 760-770.

Allen, J.L., Sorbel, B., 2008. Assessing the differenced normalized burn ratio's ability to map burn severity in the boreal forest and tundra ecosystems of Alaska's national parks. Int. J. Wildland Fire 17, 463-475.

Arora, V.K., Boer, G.J., 2005. Fire as an interactive component of dynamic vegetation models. J. Geophys. Res. Biogeosci. 110.

Bartels, S.F., Chen, H.Y., Wulder, M.A., White, J.C., 2016. Trends in post-disturbance recovery rates of Canada's forests following wildfire and harvest. For. Ecol. Manag. 361, 194-207.

Bolton, D.K., Coops, N.C., Wulder, M.A., 2015. Characterizing residual structure and forest recovery following high-severity fire in the western boreal of Canada using Landsat time-series and airborne lidar data. Remote Sens. Environ. 163, 48-60.

Bond, W.J., Woodward, F.I., Midgley, G.F., 2005. The global distribution of ecosystems in a world without fire. New Phytol. 165, 525-538.

Bowman, D.M., Balch, J.K., Artaxo, P., Bond, W.J., Carlson, J.M., Cochrane, M.A., D'Antonio, C.M., DeFries, R.S., Doyle, J.C., Harrison, S.P., Johnston, F.H., Keeley, J.E., Krawchuk, M.A., Kull, C.A., Marston, J.B., Moritz, M.A., Prentice, I.C., Roos, C.I., Scott, A.C., Swetnam, T.W., Werf, G.R.v.d., Pyne, S.J., 2009. Fire in the earth system. Science 324, 481-484.

Canadian Forest Service, 2015. Canadian National Fire Database - Agency Fire Data. C.F.S. Natural Resources Canada, Northern Forestry Centre, Edmonton, Alberta.

Carroll, M., Townshend, J., Hansen, M., DiMiceli, C., Sohlberg, R., Wurster, K., 2010. MODIS vegetative cover conversion and vegetation continuous fields. In: Land Remote Sensing and Global Environmental Change. Springer, pp. 725-745.

Cheng, Y., Gamon, J.A., Fuentes, D.A., Mao, Z., Sims, D.A., Qiu, H.-l., Claudio, H., Huete, A., \& Rahman, A.F., 2006. A multi-scale analysis of dynamic optical signals in a Southern California chaparral ecosystem: a comparison of field, AVIRIS and MODIS data. Remote Sens. Environ. 103, 369-378.

Chu, T., Guo, X., 2013. Remote sensing techniques in monitoring post-fire effects and patterns of forest recovery in boreal forest regions: a review. Remote Sens. 6, 470-520.

Chu, T., Guo, X., Takeda, K., 2017. Effects of burn severity and environmental conditions on post-fire regeneration in Siberian larch forest. Forests 8, 76.

Chuvieco, E., Giglio, L., Justice, C., 2008. Global characterization of fire activity: toward defining fire regimes from earth observation data. Glob. Chang. Biol. 14, 1488-1502.

Chuvieco, E., Yue, C., Heil, A., Mouillot, F., Alonso-Canas, I., Padilla, M., Pereira, J.M., 
Oom, D., Tansey, K., 2016. A new global burned area product for climate assessment of fire impacts. Glob. Ecol. Biogeogr. 25, 619-629.

Cuevas-Gonzáles, M., Gerard, F., Balzter, H., Riano, D., 2009. Analysing forest recovery after wildfire disturbance in boreal Siberia using remotely sensed vegetation indices. Glob. Chang. Biol. 15, 561-577.

Dennison, P.E., Brewer, S.C., Arnold, J.D., Moritz, M.A., 2014. Large wildfire trends in the western United States, 1984-2011. Geophys. Res. Lett. 41, 2928-2933.

Díaz-Delgado, R., Lloret, F., Pons, X., 2003. Influence of fire severity on plant regeneration by means of remote sensing imagery. Int. J. Remote Sens. 24, 1751-1763.

Eidenshink, J.C., Schwind, B., Brewer, K., Zhu, Z.-L., Quayle, B., Howard, S.M., 2007. A project for monitoring trends in burn severity. Fire Ecol. 3, 3-21.

Epting, J., Verbyla, D., 2005. Landscape-level interactions of prefire vegetation, burn severity, and postfire vegetation over a 16-year period in interior Alaska. Can. J. For. Res. 35, 1367-1377.

Fernandez-Manso, A., Quintano, C., Roberts, D.A., 2016. Burn severity influence on postfire vegetation cover resilience from Landsat MESMA fraction images time series in Mediterranean forest ecosystems. Remote Sens. Environ. 184, 112-123.

Fisher, R.A., Muszala, S., Verteinstein, M., Lawrence, P., Xu, C., McDowell, N.G., Knox, R.G., Koven, C., Holm, J., Rogers, B.M., Spessa, A., Lawrence, D., Bonan, G., 2015. Taking off the training wheels: the properties of a dynamic vegetation model without climate envelopes, CLM4. 5 (ED). Geosci. Model Dev. 8, 3593-3619.

Franklin, J., Spears-Lebrun, L.A., Deutschman, D.H., Marsden, K., 2006. Impact of a highintensity fire on mixed evergreen and mixed conifer forests in the Peninsular Ranges of southern California, USA. For. Ecol. Manag. 235, 18-29.

Friedl, M.A., Sulla-Menashe, D., Tan, B., Schneider, A., Ramankutty, N., Sibley, A., Huang, X., 2010. MODIS collection 5 global land cover: algorithm refinements and characterization of new datasets. Remote Sens. Environ. 114, 168-182.

Giglio, L., Descloitres, J., Justice, C.O., Kaufman, Y.J., 2003. An enhanced contextual fire detection algorithm for MODIS. Remote Sens. Environ. 87, 273-282.

Goetz, S.J., Bunn, A.G., Fiske, G.J., Houghton, R., 2005. Satellite-observed photosynthetic trends across boreal North America associated with climate and fire disturbance. Proc. Natl. Acad. Sci. U. S. A. 102, 13521-13525.

Goetz, S.J., Fiske, G.J., Bunn, A.G., 2006. Using satellite time-series data sets to analyze fire disturbance and forest recovery across Canada. Remote Sens. Environ. 101, 352-365.

Goetz, S., Mack, M., Gurney, K., Randerson, J., Houghton, R., 2007. Ecosystem responses to recent climate change and fire disturbance at northern high latitudes: observations and model results contrasting northern Eurasia and North America. Environ. Res. Lett. 2, 045031.

Hall, R.J., Freeburn, J., De Groot, W., Pritchard, J., Lynham, T., Landry, R., 2008. Remote sensing of burn severity: experience from western Canada boreal fires. Int. J. Wildland Fire 17, 476-489.

Hansen, M., DeFries, R., Townshend, J., Sohlberg, R., Dimiceli, C., Carroll, M., 2002. Towards an operational MODIS continuous field of percent tree cover algorithm: examples using AVHRR and MODIS data. Remote Sens. Environ. 83, 303-319.

Hansen, M., DeFries, R., Townshend, J., Carroll, M., Dimiceli, C., Sohlberg, R., 2003. Global percent tree cover at a spatial resolution of 500 meters: first results of the MODIS vegetation continuous fields algorithm. Earth Interact. 7, 1-15.

Hansen, M.C., Potapov, P.V., Moore, R., Hancher, M., Turubanova, S.A., Tyukavina, A., Thau, D., Stehman, S.V., Goetz, S.J., Loveland, T.R., Kommareddy, A., Egorov, A., Chini, L., Justice, C.O., Townshend, J.R.G., 2013. High-resolution global maps of 21st-century forest cover change. Science 342, 850-853.

Hantson, S., Arneth, A., Harrison, S., Kelley, D., Prentice, I.C., Rabin, S., Archibald, S., Mouillot, F., Arnold, S., Artaxo, P., Bachelet, D., Ciais, P., Forrest, M., Friedlingstein, P., Hickler, T., Kaplan, J., Kloster, S., Knorr, W., Lasslop, G., Li, F., Mangeon, S., Melton, J., Meyn, A., Sitch, S., Spessa, A., van der Werf, G., Voulgarakis, A., Yue, C., 2016. The status and challenge of global fire modelling. Biogeosciences 13, 3359-3375.

Hicke, J.A., Asner, G.P., Kasischke, E.S., French, N.H., Randerson, J.T., James Collatz, G., Stocks, B.J., Tucker, C.J., Los, S.O., Field, C.B., 2003. Postfire response of North American boreal forest net primary productivity analyzed with satellite observations. Glob. Chang. Biol. 9, 1145-1157.

Huete, A., Didan, K., Miura, T., Rodriguez, E.P., Gao, X., Ferreira, L.G., 2002. Overview of the radiometric and biophysical performance of the MODIS vegetation indices. Remote Sens. Environ. 83, 195-213.

Jin, Y., Randerson, J.T., Goetz, S.J., Beck, P.S., Loranty, M.M., Goulden, M.L., 2012. The influence of burn severity on postfire vegetation recovery and albedo change during early succession in North American boreal forests. J. Geophys. Res. Biogeosci. 117.

Johnstone, J., Chapin III, F., 2006. Fire interval effects on successional trajectory in boreal forests of northwest Canada. Ecosystems 9, 268-277.

Joiner, J., Yoshida, Y., Vasilkov, A.P., Schaefer, K., Jung, M., Guanter, L., Zhang, Y., Garrity, S., Middleton, E.M., Huemmrich, K.F., Gu, L., Marchesini, L.B., 2014. The seasonal cycle of satellite chlorophyll fluorescence observations and its relationship to vegetation phenology and ecosystem atmosphere carbon exchange. Remote Sens. Environ. 152, 375-391.

Kasischke, E.S., Turetsky, M.R., 2006. Recent changes in the fire regime across the North American boreal region-spatial and temporal patterns of burning across Canada and Alaska. Geophys. Res. Lett. 33.

Keeley, J.E., Pausas, J.G., Rundel, P.W., Bond, W.J., Bradstock, R.A., 2011. Fire as an evolutionary pressure shaping plant traits. Trends Plant Sci. 16, 406-411.

Kelley, D.I., Prentice, I.C., Harrison, S.P., Wang, H., Simard, M., Fisher, J.B., Willis, K.O., 2013. A comprehensive benchmarking system for evaluating global vegetation models. Biogeosciences 10, 3313-3340.

Key, C.H., Benson, N.C., 2006. Landscape assessment (LA). FIREMON: fire effects monitoring and inventory system. In: Gen. Tech. Rep. RMRS-GTR-164-CD. US Department of Agriculture, Forest Service, Rocky Mountain Research Station, Fort Collins, CO.
Kolden, C.A., Smith, A.M., Abatzoglou, J.T., 2015. Limitations and utilisation of monitoring trends in burn severity products for assessing wildfire severity in the USA. Int. J. Wildland Fire 24, 1023-1028.

Krylov, A., McCarty, J.L., Potapov, P., Loboda, T., Tyukavina, A., Turubanova, S., Hansen, M.C., 2014. Remote sensing estimates of stand-replacement fires in Russia, 2002-2011. Environ. Res. Lett. 9, 105007.

Lasslop, G., Thonicke, K., Kloster, S., 2014. SPITFIRE within the MPI earth system model: model development and evaluation. J. Adv. Model. Earth Syst. 6, 740-755.

van Leeuwen, T.T., van der Werf, G.R., Hoffmann, A.A., Detmers, R.G., Rücker, G., French, N.H.F., Archibald, S., Carvalho, J.A., Cook, G.D., de Groot, W.J., Hély, C., Kasischke, E.S., Kloster, S., McCarty, J.L., Pettinari, M.L., Savadogo, P., Alvarado, E.C., Boschetti, L., Manuri, S., Meyer, C.P., Siegert, F., Trollope, L.A., Trollope, W.S.W., 2014. Biomass burning fuel consumption rates: a field measurement database. Biogeosciences 11, 7305-7329.

Lentile, L.B., Holden, Z.A., Smith, A.M., Falkowski, M.J., Hudak, A.T., Morgan, P., Lewis, S.A., Gessler, P.E., Benson, N.C., 2006. Remote sensing techniques to assess active fire characteristics and post-fire effects. Int. J. Wildland Fire 15, 319-345.

Lentile, L.B., Smith, A.M., Hudak, A.T., Morgan, P., Bobbitt, M.J., Lewis, S.A., Robichaud, P.R., 2009. Remote sensing for prediction of 1-year post-fire ecosystem condition. Int. J. Wildland Fire 18, 594-608.

Li, F., Zeng, X., Levis, S., 2012. A process-based fire parameterization of intermediate complexity in a dynamic global vegetation model. Biogeosciences 9, 2761-2780.

Li, F., Lawrence, D.M., Bond-Lamberty, B., 2017. Impact of fire on global land surface air temperature and energy budget for the 20th century due to changes within ecosystems. Environ. Res. Lett. 12, 044014.

Littell, J.S., Peterson, D.L., Riley, K.L., Liu, Y., Luce, C.H., 2016. A review of the relationships between drought and forest fire in the United States. Glob. Chang. Biol. 2353-2369.

Loboda, T., O'neal, K., Csiszar, I., 2007. Regionally adaptable dNBR-based algorithm for burned area mapping from MODIS data. Remote Sens. Environ. 109, 429-442.

Lyapustin, A., Martonchik, J., Wang, Y., Laszlo, I., Korkin, S., 2011. Multiangle implementation of atmospheric correction (MAIAC): 1. Radiative transfer basis and look-up tables. J. Geophys. Res. Atmos. 116.

Magnussen, S., Wulder, M.A., 2012. Post-fire canopy height recovery in Canada's boreal forests using Airborne Laser Scanner (ALS). Remote Sens. 4, 1600-1616.

McCarley, R., Kolden, C., Vaillant, N., Hudak, A., Smith, A., Wing, B., Kellogg, B., Kreitler, J., 2017. Multi-temporal LiDAR and Landsat quantification of fire-induced changes to forest structure. Remote Sens. Environ. 191, 419-432.

McMichael, C., Hope, A., Roberts, D., Anaya, M., 2004. Post-fire recovery of leaf area index in California chaparral: a remote sensing-chronosequence approach. Int. J. Remote Sens. 25, 4743-4760.

Meng, R., Dennison, P.E., Huang, C., Moritz, M.A., D'Antonio, C., 2015. Effects of fire severity and post-fire climate on short-term vegetation recovery of mixed-conifer and red fir forests in the Sierra Nevada Mountains of California. Remote Sens. Environ. $171,311-325$.

Meng, R., Wu, J., Schwager, K.L., Zhao, F., Dennison, P.E., Cook, B.D., Brewster, K. Green, T.M., Serbin, S.P., 2017. Using high spatial resolution satellite imagery to map forest burn severity across spatial scales in a Pine Barrens ecosystem. Remote Sens. Environ. 191, 95-109.

Miller, J.D., Thode, A.E., 2007. Quantifying burn severity in a heterogeneous landscape with a relative version of the delta Normalized Burn Ratio (dNBR). Remote Sens. Environ. 109, 66-80.

Mitchell, R.J., Liu, Y., O'Brien, J.J., Elliott, K.J., Starr, G., Miniat, C.F., Hiers, J.K., 2014 Future climate and fire interactions in the southeastern region of the United States. For. Ecol. Manag. 327, 316-326.

Morton, D.C., Nagol, J., Carabajal, C.C., Rosette, J., Palace, M., Cook, B.D., Vermote, E.F., Harding, D.J., North, P.R., 2014. Amazon forests maintain consistent canopy structure and greenness during the dry season. Nature 506, 221-224.

Olson, D.M., Dinerstein, E., Wikramanayake, E.D., Burgess, N.D., Powell, G.V., Underwood, E.C., D'amico, J.A., Itoua, I., Strand, H.E., Morrison, J.C., 2001. Terrestrial ecoregions of the world: a new map of life on earth a new global map of terrestrial ecoregions provides an innovative tool for conserving biodiversity. Bioscience 51, 933-938.

Pettinari, M.L., Chuvieco, E., 2016. Generation of a global fuel data set using the fuel characteristic classification system. Biogeosciences 13, 2061-2076.

Pfeiffer, M., Spessa, A., Kaplan, J.O., 2013. A model for global biomass burning in preindustrial time: LPJ-LMfire (v1, 0). Geosci. Model Dev, 6, 643-685.

Quinn, R.D., Keeley, S.C., 2006. Introduction to California Chaparral. 90 Univ of California Press.

Quintano, C., Fernández-Manso, A., Roberts, D.A., 2013. Multiple Endmember Spectral Mixture Analysis (MESMA) to map burn severity levels from Landsat images in Mediterranean countries. Remote Sens. Environ. 136, 76-88.

Randerson, J.T., Liu, H., Flanner, M.G., Chambers, S.D., Jin, Y., Hess, P.G., Pfister, G., Mack, M., Treseder, K., Welp, L., Chapin, F.S., Harden, J.W., Goulden, M.L., Lyons, E., Neff, J.C., Schuur, E.A.G., Zender, C.S., 2006. The impact of boreal forest fire on climate warming. Science 314, 1130-1132.

Rogers, B., Randerson, J., Bonan, G., 2013. High-latitude cooling associated with landscape changes from North American boreal forest fires. Biogeosciences 10, 669-718.

Rogers, B.M., Soja, A.J., Goulden, M.L., Randerson, J.T., 2015. Influence of tree species on continental differences in boreal fires and climate feedbacks. Nat. Geosci. 8, 228-234.

Sitch, S., Smith, B., Prentice, I.C., Arneth, A., Bondeau, A., Cramer, W., Kaplan, J., Levis, S., Lucht, W., Sykes, W., Thonicke, K., Venevsky, S., 2003. Evaluation of ecosystem dynamics, plant geography and terrestrial carbon cycling in the LPJ dynamic global vegetation model. Glob. Chang. Biol. 9, 161-185.

Stocks, B., Mason, J., Todd, J., Bosch, E., Wotton, B., Amiro, B., Flannigan, M., Hirsch, K., Logan, K., Martell, D., Skinner, W., 2002. Large forest fires in Canada, 1959-1997. J. 
Geophys. Res. Atmos. 107.

Storey, E.A., Stow, D.A., O'Leary, J.F., 2016. Assessing postfire recovery of chamise chaparral using multi-temporal spectral vegetation index trajectories derived from Landsat imagery. Remote Sens. Environ. 183, 53-64.

Thompson, J.R., Spies, T.A., 2009. Vegetation and weather explain variation in crown damage within a large mixed-severity wildfire. For. Ecol. Manag. 258, 1684-1694.

Thonicke, K., Spessa, A., Prentice, I.C., Harrison, S.P., Dong, L., Carmona-Moreno, C., 2010. The influence of vegetation, fire spread and fire behaviour on biomass burning and trace gas emissions: results from a process-based model. Biogeosciences 7, 1991-2011.

Tian, H., Lu, C., Ciais, P., Michalak, A.M., Canadell, J.G., Saikawa, E., Huntzinger, D.N., Gurney, K.R., Sitch, S., Zhang, B., Yang, J., Bousquet, P., Bruhwiler, L., Chen, G., Dlugokencky, E., Friedlingstein, P., Melillo, J., Pan, S., Poulter, B., Prinn, R., Saunois, M., Schwalm, C.R., Wofsy, S.C., 2016. The terrestrial biosphere as a net source of greenhouse gases to the atmosphere. Nature 531, 225-228.

Turner, M.G., Romme, W.H., Gardner, R.H., 2000. Prefire heterogeneity, fire severity, and early postfire plant reestablishment in subalpine forests of Yellowstone National Park, Wyoming. Int. J. Wildland Fire 9, 21-36.

Turner, M.G., Romme, W.H., Tinker, D.B., 2003. Surprises and lessons from the 1988 Yellowstone fires. Front. Ecol. Environ. 1, 351-358.

Veraverbeke, S., Lhermitte, S., Verstraeten, W., Goossens, R., 2010. The temporal dimension of differenced Normalized Burn Ratio (dNBR) fire/burn severity studies: the case of the large 2007 Peloponnese wildfires in Greece. Remote Sens. Environ. 114, $2548-2563$.

Vermote, E.F., El Saleous, N.Z., Justice, C.O., 2002. Atmospheric correction of MODIS data in the visible to middle infrared: first results. Remote Sens. Environ. 83, 97-111.

Viedma, O., Quesada, J., Torres, I., De Santis, A., Moreno, J.M., 2015. Fire severity in a large fire in a Pinus pinaster forest is highly predictable from burning conditions, stand structure, and topography. Ecosystems 18, 237-250.

Ward, D., Kloster, S., Mahowald, N., Rogers, B., Randerson, J., Hess, P., 2012. The changing radiative forcing of fires: global model estimates for past, present and future. Atmos. Chem. Phys. 12.

van der Werf, G.R., Randerson, J.T., Giglio, L., Collatz, G., Mu, M., Kasibhatla, P.S., Morton, D.C., DeFries, R., Jin, Y.v., van Leeuwen, T.T., 2010. Global fire emissions and the contribution of deforestation, savanna, forest, agricultural, and peat fires (1997-2009). Atmos. Chem. Phys. 10, 11707-11735.

Westerling, A.L., Hidalgo, H.G., Cayan, D.R., Swetnam, T.W., 2006. Warming and earlier spring increase western US forest wildfire activity. Science 313, 940-943.

White, J.D., Ryan, K.C., Key, C.C., Running, S.W., 1996. Remote sensing of forest fire severity and vegetation recovery. Int. J. Wildland Fire 6, 125-136.

Wimberly, M.C., Reilly, M.J., 2007. Assessment of fire severity and species diversity in the southern Appalachians using Landsat TM and ETM + imagery. Remote Sens. Environ. 108, 189-197.

Wulder, M., White, J., Alvarez, F., Han, T., Rogan, J., Hawkes, B., 2009. Characterizing boreal forest wildfire with multi-temporal Landsat and LIDAR data. Remote Sens, Environ. 113, 1540-1555.

Yang, J., Weisberg, P.J., Bristow, N.A., 2012. Landsat remote sensing approaches for monitoring long-term tree cover dynamics in semi-arid woodlands: comparison of vegetation indices and spectral mixture analysis. Remote Sens. Environ. 119, 62-71.

Yang, J., Tian, H., Tao, B., Ren, W., Kush, J., Liu, Y., Wang, Y., 2014. Spatial and temporal patterns of global burned area in response to anthropogenic and environmental factors: reconstructing global fire history for the 20th and early 21 st centuries. J. Geophys. Res. Biogeosci. 119, 249-263.

Yang, J., Tian, H., Tao, B., Ren, W., Lu, C., Pan, S., Wang, Y., Liu, Y., 2015a. Century-scale patterns and trends of global pyrogenic carbon emissions and fire influences on terrestrial carbon balance. Glob. Biogeochem. Cycles 29, 1549-1566.

Yang, J., Tian, H., Tao, B., Ren, W., Pan, S., Liu, Y., Wang, Y., 2015b. A growing importance of large fires in conterminous United States during 1984-2012. J. Geophys. Res. Biogeosci. 120, 2625-2640.

Zhao, F., Meng, R., Huang, C., Zhao, M., Zhao, F.A., Gong, P., Yu, L., Zhu, Z., 2016. Longterm post-disturbance forest recovery in the greater Yellowstone ecosystem analyzed using Landsat time series stack. Remote Sens. 8, 898. 